\title{
Active Funds and Bundled News
}

\begin{abstract}
We use trade-level data to examine the role of actively managed funds (AMFs) in earnings news dissemination. AMFs trade 170 percent more on earnings announcement (EA) days than on nonEA days. Abnormal AMF participation is disproportionately higher when earnings news is bundled with management guidance about future earnings. When the two pieces of information are directionally inconsistent, AMFs trade in the direction of guidance news rather than current earnings news. They exhibit an ability to discern, and adapt their trading to, the bias in managerial guidance. Further, we find that increased AMF trading during EAs reduces post-guidance price drift and leads to faster price adjustment. Collectively, our findings suggest AMFs are relatively sophisticated processors of bundled EA news, and their trading generally improves market price discovery.
\end{abstract}

Keywords: actively managed funds, earnings announcements, management forecasts, information processing, price efficiency, trading volume

JEL Classifications: G12, G14, G23, M41 


\section{INTRODUCTION}

In this study, we examine the response of active fund managers to information released at earnings announcements (EAs). An estimated $\$ 58.4$ trillion was run by active fund managers in 2015 and this number is estimated to grow to $\$ 74$ trillion by 2020 (PricewaterhouseCoopers 2017). However, surprisingly little is known about how actively managed funds (AMFs) respond to key sources of information at the release of corporate earnings. ${ }^{1}$ Using trade-level data, we analyze the magnitude of AMF trading during EAs and provide new insights into their specific information processing skills.

Our findings link AMF trading at EAs to the nature and direction of managerial guidance released during these events. Prior literature has documented an increased tendency for firms to "bundle" managerial forecasts with the release of earnings news. ${ }^{2}$ These bundled news releases appear to play a significant role in the documented increase in the information content of EAs (Anilowski, Feng, and Skinner 2007; Ball and Shivakumar 2008; Rogers and Van Buskirk 2013). Our empirical analysis shows that AMFs are particularly efficient at processing information about future earnings (i.e., the information contained in bundled guidance). Furthermore, we show that their information processing of management guidance contributes to the speed of price adjustment at the EA.

We have two motives for studying the AMF reaction to earnings releases. First, we are interested in evaluating the extent to which AMF trades reflect sophisticated processing of specific

\footnotetext{
${ }^{1}$ Our AMF sample includes both mutual funds (MFs) that cater to retail investors and other active fund managers that cater to institutional clients. These AMFs typically hold long-only portfolios and do not engage in short-selling. A relatively small portion of the trades in our data are by known hedge funds. We remove these hedge fund trades when conducting our analyses.

${ }^{2}$ The increased use of bundling may be related to litigation risk management. Bliss, Partnoy, and Furchtgott (2018) examine the likelihood of litigation in the context of earnings restatements. They show that non-bundled restatements are 5.94 times more likely to result in litigation. They attribute this result to the confounding effect of bundling, which makes it more difficult for plaintiffs to establish loss causation, leading to lower litigation risk.
} 
pieces of information released at the EA. Prior research has documented multiple behavioral biases of individual investors, which lead to economically significant losses (Barber and Odean 2000; Barber, Lee, Liu, and Odean 2009a; Barber, Odean, and Zhu 2009b). ${ }^{3}$ Blankespoor, deHaan, Wertz, and Zhu (2019) find that individual investors tend to disregard earnings information, potentially due to the high costs of incorporating such information into a trading strategy. AMFs are managed by investment professionals, who charge active fees and are presumably more sophisticated information processors. Yet prior studies on AMFs' ability to add investment value have yielded surprisingly mixed results. ${ }^{4}$ We use an event study setting to provide new evidence on AMF skill in processing earnings-related information.

Our analysis focuses particularly on AMFs' ability to process the managerial forecast information that is frequently bundled in earnings releases. Management guidance is a form of voluntary disclosure that is increasingly released concurrently with corporate earnings. Recent evidence suggests such guidance may be strategically biased (Rogers and Stocken 2005; Baginski, Campbell, Ryu, and Warren 2019). While the forward-looking information contained in such guidance is clearly relevant, the accompanying managerial bias gives rise to reliability issues that may confound less sophisticated investors. We examine the ability of AMFs to parse out bundled guidance news from EAs. ${ }^{5}$ Some prior research suggests AMFs are sophisticated processors of earnings information. ${ }^{6}$ Our findings directly link this form of institutional sophistication to AMFs'

\footnotetext{
${ }^{3}$ For example, individual investors are known to trade too much. They also tend to overreact to salient news events, leading to short term price reactions that reverse over subsequent months (e.g., Barber and Odean 2008; Da, Engelberg, and Gao 2011). Individual investors also underreact to earnings, contributing to the post earnings announcement drift (PEAD) (Bhattacharya 2001; Battalio and Mendenhall 2005).

${ }^{4}$ The evidence on mutual fund (MF) performance is particularly damning, with some studies finding that even their gross returns underperform those of passive benchmarks (Jensen 1968; Malkiel 1995; French 2008; Fama and French 2010). However, these results seem quite sensitive to the choice of benchmark (Lehman and Modest 1987; Carhart 1997; Daniel, Grinblatt, Titman, and Wermers 1997; Kothari and Warner 2001).

${ }^{5}$ We calculate unexpected guidance news using the conditional expectations model based on the current period unexpected earnings, following Rogers and Van Buskirk (2013).

${ }^{6}$ For example, prior studies find that institutional investors process current earnings information efficiently (e.g., Ke
} 
ability to parse out and interpret the forward-looking information in bundled managerial guidance.

A second reason to study AMF reaction to EAs stems from the broader issue of market efficiency. The issue of whether institutional investors help correct market mispricing has been widely debated. Some evidence suggests that institutional investors fail to take advantage of various pricing anomalies, and in some cases may even exacerbate them (Lewellen 2011; Edelen, Ince, and Kadlec 2016; Arif, Ben-Rephael, and Lee 2017). Other studies find that higher institutional trading, ownership, or attention can improve price discovery. ${ }^{7}$ However, none of these studies examine the role of AMF trading in the incorporation of value-relevant information in managerial guidance releases. Building on the evidence in Ng, Tuna, and Verdi (2013) that shows a sluggish incorporation of guidance news into price, we show that AMF participation and trading during the EA significantly improves the incorporation of guidance news into price.

We address our research questions by combining an event study setting with the use of highly granular trade-level data. One reason for the mixed prior results on the performance of AMF managers could be the low power of portfolio-based performance measures. As noted by Grinblatt and Titman (1994) and Kothari and Warner (2001), portfolio returns are noisy and the tests based on portfolio returns may not detect abnormal asset manager skill even if it exists. ${ }^{8}$ Kothari and Warner (2001), in particular, note that an event study would provide a much more powerful setting for evaluating the information processing ability of asset managers. We combine

and Ramalingegowda 2005); other studies suggest mutual fund trades predict future earnings (Baker, Litov, Wachter, and Wurgler 2010; Chen, Huang, and Jiang 2019).

${ }^{7}$ For example, Cheng, Hameed, Subrahmanyam, and Titman (2017) find that the magnitudes of short-term return reversals are higher following declines in the number of active institutional investors. Similarly, institutional ownership or attention is negatively correlated with the size of the post-earnings announcement drift (PEAD) (Bartov, Radhakrishnan, and Krinsky 2000; Hou, Xiong, and Peng 2009). Greater institutional attention to news, as measured by Bloomberg terminal searches and the number of news reads, is associated with improved price discovery (Ben-Rephael, Da, and Israelsen 2017).

${ }^{8}$ Grinblatt and Titman (1994) address this concern by relying on priors about fund characteristics that determine performance, and Kothari and Warner (2001) recommend using time-series datasets on MF holdings to overcome the power issue. 
this insight with detailed data on AMF trades, which allow us to pin down precisely the timing and direction (i.e., buyer-initiated vs. seller-initiated nature) of each AMF transaction.

The event study setting also helps to mitigate concerns about the effect of "flow-induced trading.” Prior studies find that an investor holding a passive market portfolio earns higher aftercost returns, on average, than the typical active fund manager (French 2008; Fama and French 2010). We argue that these results do not necessarily imply a lack of skill in AMF managers. AMFs trade for many reasons, and investor flows and the size of funds could drive the underperformance of actively managed portfolios (Berk and Green 2004; Coval and Stafford 2007; Frazzini and Lamont 2008; Lou 2012). By focusing on the abnormal AMF trading around EAs, our research design reduces the likelihood that the trades we examine are undertaken for liquidityrelated reasons.

Our analysis is aided by a unique dataset from Abel Noser Solutions (formerly Ancerno Limited), a widely recognized consulting firm that provides transaction cost monitoring services to a large set of institutional clients. The Ancerno dataset consists of all trades made by Abel Noser's sizeable client base from January 2003 to December 2010. ${ }^{9}$ Prior research (e.g., Puckett and Yan 2011) shows that the characteristics of stocks held and traded by Ancerno’s institutional clients are not significantly different from the characteristics of stocks held and traded by the average 13F-filing institution. The trades in Ancerno account for around 12 percent of CRSP volume (Hu, Jo, Wang, and Xie 2018). We define AMF trades as those conducted by Ancerno’s non-pension fund clients (clienttype=2), after removing a set of known hedge funds (Jame 2018). Based on conversations with Ancerno, most of the clienttype=2 trades are made by mutual funds

\footnotetext{
${ }^{9}$ During this sample period, Ancerno data featured individual client identifiers. While actual client names have been redacted, these identifier codes allow us to track the trades made by each unique client identification code over time. After 2010, Ancerno data did not contain individual client identification codes.
} 
(MFs), but this category may also include some funds that manage money for institutions (other than pension funds). To be safe, we therefore refer to this group of traders as AMFs rather than MFs. ${ }^{10}$

Our analysis reveals several key findings. First, we document a significant AMF reaction to EAs, particularly when bundled guidance is released. On average, AMFs place 170 percent more trades on the EA day (Day 0) than on adjacent non-EA days, where adjacent non-EA days are defined as days $[-25,-2]$ and $[+5,+25]$ relative to the EA. Controlling for the magnitude of the current earnings surprise, AMF trading volume at the EA is significantly higher when there is a bundled management forecast. Prior research report that market reactions to current earnings are stronger than those to concurrently disclosed future guidance (Atiase, Li, Supattarakul, and Tse 2005). We confirm this finding and further show that, in contrast to the average market participant, AMFs respond more to the presence of guidance news and less to the magnitude of earnings news. Next, we examine AMFs' information processing abilities with respect to both current earnings news and guidance news. ${ }^{11}$ Focusing more narrowly on only EAs with bundled guidance, we show that non-directional AMF trading volume increases with the magnitude of the unexpected guidance news. Relative to total trading volume, the AMF trading volume responds less to the magnitude of unexpected earnings, and more to the magnitude of unexpected guidance. Prior literature has found that managers tend to offset good and bad news (Waymire 1984; Segal and Segal 2016). We find that AMFs do not respond to earnings news when it is inconsistent in direction to guidance news, whereas the average market participant still responds to the magnitude of earnings news even when it is directionally inconsistent with guidance news.

\footnotetext{
${ }^{10}$ In fact, there is little conceptual distinction between MFs and other AMFs. Prior literature on AMF performance likely focused on MFs because these funds are easier to identify through their 13F filings.

${ }^{11}$ Not only are $90 \%$ of management forecasts issued concurrently with earnings, but non-bundled guidance often occurs with other events that can "contaminate" or "confound" the analysis (Billings, Jennings, and Lev 2015).
} 
We then focus more sharply on the effect of directional AMF trades - i.e., the net buy-sell imbalance in AMF trades. This test is important because it provides a more direct link between the AMF trades and the sign and magnitude of the information released at the EA. We find that AMFs generally trade in the same direction as both unexpected earnings and unexpected guidance, which suggests their trading activities are not merely supplying liquidity. Furthermore, when unexpected earnings and unexpected guidance are directionally inconsistent, AMFs trade in the direction of unexpected guidance rather than unexpected earnings. These tests support the hypothesis that AMFs are particularly sophisticated processors of guidance news. Choi, Myers, Zang, and Ziebart (2011) report that future earnings response coefficients (FERCs) are greater for forecasting firms and when forecasts are more frequent and more precise. Our results suggest AMF trading may be one channel through which markets incorporate guidance news into prices.

Given prior research that documents managers' strategic incentives to bias guidance, we also calculate the guidance bias based on future realized earnings. Our results show that AMFs seem to have an ability to detect the magnitude of guidance bias. Specifically, we find that when the magnitude of the guidance bias is larger, AMFs trade less. The reduction in AMF volume is disproportionately large relative to the reduction in volume for all market participants. Furthermore, in more detailed analyses using directional AMF volume, we show that AMFs buy less when managerial guidance is highly optimistically biased. This result is in sharp contrast to the directional response for the aggregate market, which exhibits no ability to discern the direction of the bias.

Finally, we show that AMF participation at the EA improves the speed of price adjustment. The fraction of the total $[0,+63]$ return that occurs in the EA period of days $[0,+4]$ is higher when AMFs trade more, measured both in absolute terms and as a fraction of total trading volume at the 
EA. ${ }^{12}$ We find that directional AMF trades also improve price discovery. Specifically, when AMFs trade in the same direction as the unexpected guidance ("concordant" trading), a much higher fraction of the returns occurs in the 5-day EA period. ${ }^{13}$ We supplement these tests with a set of analyses showing that the post-guidance price drift (Ng et al. 2013) exists only when: (a) AMF participation in terms of total volume is low, or (b) when AMF trading is not directionally concordant to the guidance news. Taken together, these findings strongly suggest that AMF trading during earnings news releases is associated with an improvement in the price discovery process.

The paper proceeds as follows. Section 2 outlines hypotheses and reviews related literature. Section 3 details our research design and provides results. Section 4 concludes.

\section{HYPOTHESIS DEVELOPMENT}

In this section, we detail what we expect to find in our analyses. Our hypotheses, stated in alternative form, are:

H1: AMFs trade in response to EAs, especially when the news release contains concurrent (i.e., “bundled”) management guidance on future earnings.

EAs provide useful fundamental information about firm value. Earlier studies document a price reaction to earnings news (Ball and Brown 1968; Beaver 1968). While these studies do not distinguish between retail and institutional investors, subsequent studies have found that institutions in particular influence a firm's information environment and price formation process (e.g., Utama and Cready 1997; El-Gazzar 1998; Jiambalvo, Rajgopal, and Venkatachalam 2002;

\footnotetext{
${ }^{12}$ For this speed of price adjustment test, we use only firms in the top or bottom quintile, as ranked by their [0,+63] returns. This ensures: (a) we focus on firm-quarters where a sufficient amount of new information has arrived, and (b) the impact of measurement noise due to small denominators is mitigated.

${ }^{13}$ We define "concordant" observations as those with the highest quintile AMF buy-sell imbalance when unexpected guidance is high (quintile 5 unexpected guidance) and the lowest quintile AMF buy-sell imbalance when unexpected guidance is low (quintile 1 unexpected guidance).
} 
Collins, Gong, and Hribar 2003). Given that EAs contain significant information regarding value of a firm, we expect AMFs to participate intensely at the EA. Cready, Kumas, and Subasi (2014) provide tangential evidence on this point in that institutions increase their trade sizes at earnings announcements. Hu, Ke, and Yu (2018) find that transient institutions sell in response to small negative earnings surprises. Relatedly, Engelberg, McLean, and Pontiff (2018) hypothesize that, if anomaly returns are due to expectation errors, anomaly portfolios should perform better on days when new information is released, because new information leads investors to update their expectations. To the extent that AMFs play a significant role in impounding this new information into price, we expect to see significant abnormal AMF trading volume around EAs.

We are particularly interested in the AMF response to EAs in which managerial guidance is bundled with the release of current earnings. Beyer, Cohen, Lys, and Walther (2010) find that $55 \%$ of accounting-based information is provided by management forecasts, highlighting the significant amount of information conveyed by these voluntary disclosures. Ball and Shivakumar (2008) report that the rise in incremental information at the EA in recent years is due, in part, to the increasing prevalence of bundled guidance during EAs. Anilowski et al. (2007) and Rogers and Van Buskirk (2013) confirm these findings. Firms that issue guidance have higher future earnings response coefficients, consistent with the information in management guidance improving investors' ability to assess future earnings (Choi et al. 2011). These findings suggest that managerial guidance is particularly relevant in evaluating future firm performance. However, despite their importance, prior evidence shows that in bundled EAs, market reactions to current earnings news are stronger than those to concurrently disclosed guidance news (Atiase et al. 2005). Most recently, Baginski et al. (2019) find that managers strategically introduce bias into the guidance they provide when releasing earnings. As a result, the usefulness of guidance news 
involves a tradeoff between relevance and reliability.

We posit that AMFs may have an information advantage in interpreting information signals that are more relevant but possibly less reliable than current earnings. If their information processing skills allow them to better assess the reliability of guidance and isolate biased or selfserving guidance, then AMFs would likely further increase their trading activities during EAs that include concurrent guidance. Examining AMF trading in a short window around the EA allows us to precisely pin down the information that AMFs are responding to. Finding a disproportionate increase in AMF trading volume related to bundled guidance announcements would also be consistent with longer-window institutional ownership preferences for guidance, as documented in Kalay (2015).

H2: AMF trading related to bundled guidance EAs reflects efficient processing of information in management guidance.

Management guidance is part of a larger corporate disclosure strategy, and managers face a plethora of incentive issues when providing guidance. For example, prior studies find that managers strategically use guidance to benefit from personal trades (Cheng and Lo 2006; Cheng, Luo, and Yue 2013), guide analysts’ expectations downward to beatable expectations (Kato, Skinner, and Kunimura 2009; Kross, Ro, and Suk 2011), and offset simultaneously released good or bad earnings news (Segal and Segal 2016; Baginski et al. 2019). Managers tend to provide selfserving forecasts, and their willingness to bias their forecasts is related to market participants’ ability to detect this bias (Rogers and Stocken 2005).

Aside from strategic behavior, managerial guidance can also be less reliable for other reasons. For example, managers may have difficulty forecasting future earnings due to high information processing costs and increased corporate complexity (Gong, Li, and Xie 2009; Xu 
2010; Gong, Li, and Wang 2011), or behavioral factors such as overconfidence (Hilary and Hsu 2011). In a similar vein, Goodman, Neamtiu, Shroff, and White (2014) find managers that make more accurate forecasts also make better corporate investment decisions, consistent with intuition that both actions require similar skills. In sum, when noise or bias is introduced into managerial guidance, either opportunistically or unintentionally, the process of ferret out its true information content becomes more difficult.

Prior literature finds mixed evidence on market participants' ability to efficiently process information in management guidance. Gong et al. (2011) report that sell-side analysts underestimate the persistence of managers' forecast errors. In contrast, Hilary, Hsu, and Wang (2014) provide evidence that some sophisticated market participants seem to understand the benefits of predictable management forecast errors. Specifically, Hilary et al. (2014) find that the level of ownership by more sophisticated investors, as well as analyst earnings forecast revisions, respond more to guidance news when the management forecast error is more consistent. We build on this literature by isolating AMF trades in a short window around the EA. Our goal is to establish a direct link between the magnitude and direction of their EA trades, and the nature and magnitude of the news contained in both managerial guidance and current period earnings.

H3: AMF trading increases the speed of price adjustment at EAs with bundled management guidance.

One manifestation of inefficient processing of guidance news is a pattern of sluggish price adjustment. Ng et al. (2013) document underreaction to management guidance in the form of a price drift. On a related note, Zhang (2012) finds that bundled management guidance with higher ex ante accuracy mitigates investors' underreaction to concurrently related earnings. We extend this literature by directly examining the extent to which AMF trading at the EA: (a) improves the 
speed of the price adjustment process and (b) reduces the price drift in the market reaction to guidance news.

If investors fully incorporate all information in earnings into price in the first few days after the EA, the fraction of longer horizon returns captured in the first few days will be high. Given the potential market price impact of AMFs, we expect their trading will more quickly incorporate earnings and guidance news into price. Therefore, the fraction of long run returns captured in the EA period will be higher when AMF trading volume as a fraction of total trading volume is high. Furthermore, when AMFs trade in the same direction as management guidance, we expect these trades to facilitate price adjustment.

Prior research has documented that EAs are significant information events during which prices correct to fundamental value. Between 25 and 30 percent of the returns to value strategies and 40 percent of the returns to accrual strategies are concentrated in the three days around EAs (Lakonishok, Shleifer, and Vishny 1994; La Porta, Lakonishok, Shleifer, and Vishny 1997; Sloan 1996). In addition, around 25 percent of momentum profits are clustered in the three days around EAs (Jegadeesh and Titman 1993). Prices adjust toward fundamental value in the EA period because fundamental information is revealed at the EA. Funds with superior stock performance around EAs, when fundamental information is released, subsequently outperform those with inferior stock performance around EAs (Jiang and Zheng 2018). To the extent that AMFs speed up price adjustment in the EA window, AMFs play an important role in the convergence of price to fundamental value.

\section{METHODOLOGY AND RESULTS}

\subsection{AMF Trading Around EAs}

We begin our sample selection by taking the intersection of Compustat, CRSP, and IBES 
data. We obtain the date and time of the EA from IBES, where the trading date of the EA is the IBES EA date if the announcement was made before or during trading hours and the first trading day after the EA date if the announcement was made after trading hours. ${ }^{14}$ We apply a liquidity filter and restrict the sample to firm-event observations with a share price greater than $\$ 3$ and market capitalization greater than $\$ 150$ million at the most recent fiscal quarter end.

We use AMF trades from Ancerno, dating from 1/1/2003 to 12/31/2010. The Ancerno dataset is uniquely suited to our setting, as it identifies the exact date and execution price of each transaction, which allows us to distinguish the trades of each institution and each fund family within the institution in the cross section and time series. The Ancerno data consist of money manager trades (client type=2) from 1997 to 2015. Although the trade-level data is available into 2015, the client identifiers, which we use to remove hedge funds from the sample, are unavailable after 2010. Post-2010, we have no data on client identifiers. For our purposes, we require identifiers, as we are interested in AMF trading behavior and therefore want to exclude a small number of hedge funds from our sample. The coverage is significantly better in the more recent period, so we choose the post-2003 period as relevant data for our analysis. Because we examine the $[-25,+25]$ window around the EA, we restrict the sample period to EA dates between 2/9/2003 and 11/22/2010. Following Keim and Madhavan (1997), we filter the data to reduce the impact of outliers and potentially corrupt entries. Specifically, we drop transactions with an execution price lower than $\$ 1$ and greater than $\$ 1,000$, and we eliminate trades from orders with an execution time greater than one month.

To exclude hedge fund trades from our sample, we use the list of identified hedge fund

\footnotetext{
14 The IBES timestamp is confirmed to be correct in a large portion of the sample (deHaan, Shevlin, and Thornock 2015). According to Table IA.4 of their paper, the EA dates during our sample period (2003-2010) have a minimum accuracy of 70.4 to 94.3 percent and a maximum of 95.9 to 98.8 percent.
} 
client-manager pairs in Ancerno from Jame (2018). ${ }^{15}$ In our 2003-2010 sample, 90.1 percent of all trades are AMF trades and 89.0 percent of client-manager pairs are AMFs. Although our analyses are based on 2003-2010 data, with which we can isolate AMF trades, our results are robust to an extension of the sample period into 2015 and pooling of AMF and hedge fund trades. Results pooling AMF and hedge fund trades are available upon request. ${ }^{16}$ We remove hedge fund trades and require at least one AMF trade in the $[-25,+25]$ window around the EA. We select only these observations, because our results may not generalize to stocks not traded by AMFs in the Ancerno client universe. Finally, we require data to calculate unexpected earnings relative to IBES analyst consensus forecasts for each firm-quarter and, for firm-quarters with bundled guidance, data to calculate unexpected guidance (following the conditional forecast news measure in Rogers and Van Buskirk 2013). Our sample selection procedure results in a total of 76,939 firm-quarter EA observations for 4,435 unique firms in this sample period.

Figure 1 presents a plot of AMF volume on each day relative to the event day, the trading date of the EA. Each bar on the plot represents the average, over all firm-quarter EAs, of the AMF volume on each day scaled by the AMF volume over the non-EA period. In Figure 1 , the $[0,+4]$ volumes, averaged across all firm-quarters, are displayed in red. The non-EA period consists of the $[-25,-2]$ and $[+5,+25]$ trading days around the EA. These volumes, averaged across all firmquarters, are displayed in gray. The maximum mean AMF trading volume occurs on Day 0 and is 170 percent higher than the average non-EA period volume. This volume tapers off in the next few days after the EA.

Descriptive statistics of the raw trading data are reported in Table 1. The mean AMF

\footnotetext{
${ }^{15}$ The Internet Appendix of Jame (2018) provides details of the procedure used to identify hedge funds.

${ }^{16}$ We note that hedge funds comprise a small portion of clienttype $=2$ trades. Hedge funds are better represented in clienttype $=1$ (plan sponsors), but we focus on clienttype $=2$ trades because we are interested in AMFs.
} 
trading volume on Day 0 is higher than the mean AMF trading volume on any other day in the EA period, and the mean EA period trading volume is higher than the mean non-EA period trading volume. We also compute measures of abnormal EA volume. These measures account for the average level trading volume for our firm-quarters. Thus, we scale either AMF or total trading volume by total trading volume in the non-EA period. Abn AMF EA Volume is the average daily AMF volume on days $[0,+4]$, scaled by average daily total volume on days $[-20,-2]$. The mean Abn AMF EA Volume is $7 \%$. Abn EA Tot Volume has a mean of $176 \%$ and is defined as the average daily total volume on days $[0,+4]$, scaled by average daily total volume on days $[-20,-2]$. Our final measure of abnormal EA volume is AMF EA Vol as a Frac of Tot Volume, which has a mean of $3 \%$ and is calculated as the average daily AMF volume as a fraction of total volume on days $[0,+4]$. We use each of these abnormal EA volume measures to develop inferences about AMF EA trading, the average market participant's EA trading, and the disproportionate trading of AMFs at EAs.

In our first set of tests, we determine whether AMFs participate disproportionately more in trading at EAs with bundled guidance. Our tests of Hypothesis 1 are based on the following OLS model:

$$
\begin{gathered}
\text { Abn EA Volume } \quad \alpha+\beta_{1} * \text { ConcurrentGuidance }+\beta_{2} * \text { Abs_UE }+\Sigma \beta_{c} * \text { Controls }_{c} \\
=\quad+\Sigma \beta_{q} * \text { YearQtr }_{q}+\varepsilon
\end{gathered}
$$

Abn EA Volume is Abn AMF EA Volume, Abn EA Tot Volume, and AMF Vol as a Frac of Tot Volume in columns (i), (ii), and (iii) of Table 2, respectively. ConcurrentGuidance is an indicator variable set to 1 if there is bundled management guidance at the EA, and Abs_UE is the absolute value of unexpected earnings relative to the analyst consensus. ${ }^{17}$ We include Controls

\footnotetext{
${ }^{17}$ We measure $U E$ relative to the analyst consensus, following evidence in Ayers, Li, and Yeung (2011) that large traders trade in the direction of analyst-based earnings surprises rather than seasonal random walk earnings surprises.
} 
for loss quarters, an indicator if management predicts a loss, market cap, the book-to-market ratio, and stock return volatility. Our control variables mirror those used by Atiase et al. (2005), and each has been associated in prior literature with the magnitude of the market reaction to earnings news. YearQtr fixed effects are included to remove the effect of any common time trends in abnormal EA volume during our sample.

Table 2, column (i) finds positive coefficients on both ConcurrentGuidance and Abs_UE. The coefficient on ConcurrentGuidance is positive and significant, which indicates abnormal trading by AMFs at the EA is greater when the EA is accompanied by a concurrent management forecast. The coefficient on Abs_UE is positive and marginally significant, indicating greater AMF participation at the EA when the magnitude of the earnings surprise is higher. The coefficients on control variables also reveal descriptively interesting observations about AMF trading at the EA. AMFs trade less at the EA for loss quarters, when management forecasts a loss in the future, when the firm is larger or has a higher book-to-market ratio, and when the stock has higher prior return volatility. Column (ii) finds similar results on our variables of interest when we use abnormal total volume at the EA as our dependent variable. The inference is that the average market participant trades more at the EA when there is concurrent guidance and when the magnitude of the earnings surprise is greater.

The dependent variable in column (iii) is AMF EA volume as a fraction of total volume, and the results of this test allow us to infer how intensely AMFs participate in the EA relative to the average market participant. Column (iii) essentially compares the coefficients in column (i) to those in column (ii). Compared to the average market participant, AMFs trade more at the EA when there is concurrent guidance and less so on the magnitude of the earnings surprise. While these results on their own do not mean that AMFs process earnings and guidance news efficiently, 
their disproportionate participation for bundled announcements suggests that they might have an information advantage relative to the average market participant in processing guidance news. ${ }^{18}$ The fact that AMFs respond less to the magnitude of the earnings news suggests they place lower importance on current earnings information, relative to other market participants. In subsequent tests we focus on EAs that contain bundled guidance, to better understand the nature of the AMFs' information advantage in processing such news.

\subsection{AMFs' Information Processing Ability at the EA}

We begin our analyses testing Hypothesis 2 by using the following OLS model, on the sample of EAs with bundled guidance only:

Abn EA Volume $=\alpha+\beta_{1} * A b s \_U G+\beta_{2} * A b s \_U E+\Sigma \beta_{c} *$ Controls $_{c}+\Sigma \beta_{q} *$ YearQtr $_{q}+\varepsilon$

where Abn EA Volume is Abn AMF EA Volume, Abn EA Tot Volume, and AMF Vol as a Frac of Tot Volume in columns (i), (ii), and (iii) of Table 3, respectively. Abs_UG is the absolute value of unexpected guidance relative to the analyst consensus forecast for the quarter or year that the management forecast pertains to, and $A b s \_U E$ is the absolute value of unexpected earnings relative to the analyst consensus. We calculate unexpected guidance using the conditional expectations model based on the current period unexpected earnings, following Rogers and Van Buskirk (2013). We include the same Controls as those in our tests of Model 1. YearQtr fixed effects are included to remove the effect of any common time trends in abnormal EA volume during our sample.

Table 3, column (i) finds a positive and significant coefficient on Abs_UG and a positive but insignificant coefficient on $A b s \_U E$. When the magnitude of the unexpected guidance is

\footnotetext{
${ }^{18}$ We find similar results during the financial crisis of 2007-2009, as well as when we remove these financial crisis years.
} 
higher, AMFs participate more at the EA. However, in contrast to the results in Table 2, within bundled guidance announcements, AMFs do not participate significantly more when the magnitude of unexpected earnings is higher. Note that when the dependent variable is abnormal total volume at the EA (see column (ii)), the coefficients on both $A b s \_U G$ and $A b s \_U E$ are positive and significant. In other words, abnormal total volume is responsive to both the magnitude of the unexpected guidance and that of the earnings surprise. In column (iii), we find that, relative to the average market participant, AMFs do not trade more on the magnitude of the unexpected guidance, but they do trade less on the magnitude of unexpected earnings. These results are consistent with evidence in Atiase et al. (2005) that investors respond more strongly to current earnings news than to guidance news. Note that just because AMFs do not trade more in response to the magnitude of unexpected earnings, does not mean that they earnings news more efficiently. To more directly address this question, our next set of tests examines EAs in which the guidance news and the earnings news are inconsistent with each other.

Table 4 reports abnormal volume when unexpected earnings (UE) and unexpected guidance news (UG) are directionally inconsistent. To construct this table, we begin with all firmquarters with in which earnings news is bundled with guidance news $(\mathrm{N}=28,731)$. We further divide this sample into announcements with positive $U E(\mathrm{~N}=23,180)$ and announcements with negative $U E(\mathrm{~N}=5,551)$. As before, we define $U E$ relative to the IBES consensus analyst forecast, and we calculate $U G$ using the conditional expectations model in Rogers and Van Buskirk (2013). The first row of Table 4, Panel A shows that $56 \%$ of bundled guidance observations have inconsistent earnings and guidance news. The second row focuses on EAs with positive $U E$ (the majority of our sample) and finds that $55 \%$ of these EAs are accompanied by negative UG. The next row shows that among EAs with a negative UE, 59\% have bundled guidance with a positive 
UG. These descriptive statistics are consistent with evidence in Segal and Segal (2016) and Baginski et al. (2019) that managers strategically bundle positive and negative news. In particular, it appears that $59 \%$ of the bundling firms that missed earnings will pair the negative earnings news with an upgrade in their forward guidance (positive $U G$ ).

In Table 4, Panel B, we report the differential volume response for EAs where UE and $U G$ are directionally inconsistent. To construct this panel, we use the indicator variable Inconsistent to denote observations where UG and UE are inconsistent. We then estimate the following model, constraining our analysis to EAs with bundled guidance only:

$$
\begin{aligned}
\text { Abn EA Volume }= & \alpha+\beta_{1} * \text { Abs_UE }+\beta_{2} * \text { Inconsistent }+\beta_{3} * A b s_{-} U E \times \text { Inconsistent } \\
& +\Sigma \beta_{c}{ }^{*} \text { Controls }_{c}+\Sigma \beta_{q}{ }^{*} \operatorname{YearQtr}_{q}+\varepsilon
\end{aligned}
$$

where Abn EA Volume is Abn AMF EA Volume, Abn EA Tot Volume, and AMF Vol as a Frac of Tot Volume in columns (i), (ii), and (iii), respectively. Abs_UE is the absolute value of unexpected earnings relative to the analyst consensus. We include the same Controls as those in our tests of Models 1 and 2. YearQtr fixed effects are included to remove the effect of any common time trends in abnormal EA volume during our sample.

In column (i), the coefficient on Abs_UE is positive and significant, indicating that AMFs trade more at the EA when the magnitude of the earnings surprise is greater, for announcements where the sign of $U E$ lines up with the sign of $U G$. The negative and significant coefficient on the interaction Abs_UE $\times$ Inconsistent suggests that AMFs respond less to $U E$ when $U E$ is directionally inconsistent with $U G$. In fact, the sum of the coefficients on Abs_UE and Abs_UE $\times$ Inconsistent is negative but insignificant (p-value $=0.767$ ), indicating that when $U E$ and $U G$ are inconsistent, abnormal AMF volume is not significantly correlated with the magnitude of $U E$. In contrast, 
column (ii) shows that the average market participant trades more at the EA when the magnitude of $U E$ is greater, even when this signal is directionally inconsistent with $U G$ (p-value of the sum of the coefficients on Abs_UE and Abs_UE $\times$ Inconsistent is 0.0002). Column (ii) reports a negative and significant coefficient on the interaction Abs_UE $\times$ Inconsistent, suggesting the market trades less on Abs_UE when $U E$ is directionally inconsistent with $U G$. While this is encouraging, the positive and significant sum of coefficients for the aggregate market reaction is in contrast to the insignificant sum in column (i). In column (iii), when the AMF EA volume as a fraction of total volume is the dependent variable, we find a negative and significant sum of coefficients on Abs_UE and Abs_UE $\times$ Inconsistent (p-value=0.0002). Relative to the average market participant, AMFs trade significantly less on the magnitude of unexpected earnings when the $U G$ and $U E$ signals are directionally inconsistent.

Our tests so far have examined nondirectional volume and magnitudes of unexpected earnings and unexpected guidance. Our next set of tests exploits an important feature of the Ancerno data that allows us to observe whether a given AMF trade was a buy or sell. We base our tests on the following model:

$$
\text { EA BSI }=\alpha+\beta_{1} * U G+\beta_{2} * U E+\Sigma \beta_{c} * \text { Controls }_{c}+\Sigma \beta_{q} * \text { YearQtr }_{q}+\varepsilon,
$$

where EA BSI is AMF EA BSI and Total EA BSI in columns (i) and (ii) of Table 5, respectively. AMF EA BSI is defined as the buy-sell imbalance of AMF trades on days $[0,+4]$ of the EA, calculated as AMF buys in that window minus AMF sells in that window, scaled by all AMF buys and sells in that window. It is set to 0 if there are no AMF trades in that window. Total EA BSI is the buy-sell imbalance of all trades on days $[0,+4]$ of the EA, calculated as total buy-initiated volume in that window minus total sell-initiated volume in that window, scaled by all buys and sells in that window. It is set to 0 if there are no trades in that window. Each trade is classified as 
a buy or a sell based on the Lee and Ready (1991) tick test. UG is the unexpected guidance, and $U E$ is the unexpected earnings. We include the same Controls as those in our tests of the previous models. YearQtr fixed effects are included to remove the effect of any common time trends in abnormal EA buy-sell imbalance during our sample.

In column (i), we find a positive and significant coefficient on $U G$, indicating that directional trading of AMFs at the EA has a positive association with unexpected guidance. In other words, AMFs buy more when unexpected guidance is more positive, and they sell more when unexpected guidance is more negative. In contrast, the coefficient on UE is insignificant. After accounting for the relation between buy-sell imbalance and $U G$, there is no significant relation between buy-sell imbalance and $U E$.

In column (ii), the inferences with Total EA BSI as the dependent variable are quite different. Neither the coefficient on $U G$ nor the coefficient on $U E$ is significant. ${ }^{19}$ Combined with the results in Table 2 of increased total volume when Abs_UE is greater, these results suggest investor are more attentive when earnings surprises are larger in magnitude, but the greater attention does not necessarily translate into efficient processing of this news (Merton 1987; Barber and Odean 2008; Brown, Hillegeist, and Lo 2009).

Our next set of tests is based on model (3) but uses directional volume and directional unexpected guidance and unexpected earnings:

$$
\begin{aligned}
\text { EA BSI }= & \alpha+\beta_{1} * \text { Unexpected }+\beta_{2} * \text { Inconsistent }+\beta_{3} * \text { Unexpected } \times \text { Inconsistent } \\
& +\Sigma \beta_{c}{ }^{*} \text { Controls }_{c}+\Sigma \beta_{q}{ }^{*} \text { YearQtr }_{q}+\varepsilon
\end{aligned}
$$

\footnotetext{
${ }^{19}$ A caveat is that the assignment of each trade as either a buy or a sell to construct Total EA BSI is noisier, compared to the measurement of AMF EA BSI. We use the Lee and Ready (1991) tick test on TAQ trading data to assign each trade as either buy- or sell-initiated for Total EA BSI, and there may be issues with using this tick test on recent data, as shown in Easley, López de Prado, and O’Hara (2012) and Johnson and So (2018).
} 
where EA BSI is AMF EA BSI and Total EA BSI in columns (i)-(ii) and (iii)-(iv) of Table 6, respectively. The Unexpected variable is UE (unexpected earnings) in columns (i) and (iii) and UG (unexpected guidance) in columns (ii) and (iv). We include the same Controls as in our previous tests. YearQtr fixed effects are included to remove the effect of any common time trends in abnormal EA buy-sell imbalance during our sample.

In Table 6 column (i), the coefficient on $U E$ is positive and significant, indicating that AMFs' buy-sell imbalance at the EA is more positive when the earnings surprise is more positive, for announcements where the sign of $U E$ lines up with the sign of $U G$. The sum of the coefficients on $U E$ and $U E \times$ Inconsistent is negative but insignificant (p-value $=0.777$ ), which suggests that AMFs do not trade more in the direction of unexpected earnings when it is inconsistent with unexpected guidance.

Table 6 column (ii) shows that AMFs' buy-sell imbalance at the EA is more positive when unexpected guidance is more positive, for announcements with consistent $U E$ and $U G$. In contrast to the results in column (i), column (ii) finds that the sum of the coefficients on $U G$ and $U G \times$ Inconsistent is positive and marginally significant (p-value $=0.067$ ), which suggests that AMFs trade in the direction of unexpected guidance even when it is directionally inconsistent with unexpected earnings. These results strikingly convey AMFs' perception of the relative importance of each of these pieces of news at the EA.

In contrast to the AMFs, the average market participant does not trade more in the direction of $U E$ when it is more positive (column iii), nor does the average market participant trade more in the direction of $U G$ when it is more positive (column iv). The sum of coefficients in both columns are insignificant, consistent with total directional trading at the EA having no relation with the magnitude of unexpected earnings or unexpected guidance, regardless of whether these two pieces 
of information are directionally consistent or inconsistent with each other. ${ }^{20}$

Our nondirectional and directional tests thus far have revealed that AMFs focus on guidance news at bundled guidance earnings announcements, and they trade in the direction of this guidance news even when it is inconsistent with earnings news. Our next set of tests assesses whether AMFs process guidance news efficiently. Specifically, we examine whether their trading behavior at the EA takes into account the potential bias embedded in guidance news. As before, we first conduct tests of nondirectional volume using the following OLS model, on the sample of EAs with bundled guidance:

$$
\begin{aligned}
\text { Abn EA Volume }=\quad & \alpha+\beta_{1} * A b s_{-} U G+\beta_{2} * A b s_{-} U E+\beta_{3} * A b s_{-} \text {Guide_Bias }+\Sigma \beta_{c} * \text { Controls }_{c} \\
& +\Sigma \beta_{q}{ }^{*} \text { YearQtr }_{q}+\varepsilon,
\end{aligned}
$$

This test follows model (2) exactly, with an additional variable Abs_Guide_Bias, which is the absolute value of the difference between the realized earnings and the management forecast for that quarter or year. Abn EA Volume is Abn AMF EA Volume, Abn EA Tot Volume, and AMF Vol as a Frac of Tot Volume in columns (i), (ii), and (iii) of Table 7, respectively. YearQtr fixed effects are included to remove the effect of any common time trends in abnormal EA volume during our sample.

In Table 7 column (i), the coefficient on Abs_Guide_Bias is negative and significant, indicating that AMFs trade less at the EA when the magnitude of the guidance bias greater. Similarly, column (ii) finds a negative and marginally significant coefficient on Abs_Guide_Bias, consistent with the average market participant trading less at the EA when the magnitude of the

\footnotetext{
${ }^{20}$ In the subsample with the crisis years of 2007-2009 removed, we find some evidence of a positive and marginally significant coefficient on $U E$, but only when it is consistent in sign with $U G$. In contrast, we do not find a significant association between Abn EA Tot Volume and $U G$, irrespective of the sign of $U E$.
} 
guidance bias is greater. ${ }^{21}$ This result is consistent with Yang (2012), who finds that investors respond less to management forecasts when the manager has lower historical accuracy. In our case, both AMFs and the average market participant seem to pull back from trading when the bias, which has yet to be realized, is greater.

In column (iii), when the dependent variable is AMF Vol as a Frac of Tot Volume, the coefficient on Abs_Guide_Bias is negative and significant, suggesting that AMFs trade disproportionately less than the average market participant when there is a greater guidance bias. Thus, at least at first blush, it appears AMFs are relatively more sensitive to the presence of a bias in managerial guidance.

We further evaluate the AMF response to guidance bias by examining their directional trading. Table 8 presents results of regressing AMF EA BSI and Total EA BSI on unexpected earnings (UE), unexpected guidance $(U G)$, and guidance bias. These tests are similar to model (6), but link the directional volume to directional $U G$ and $U E$, as well as directional guidance bias. Specifically, we estimate the following equation:

$$
\begin{aligned}
\text { EA BSI }=\quad & \alpha+\beta_{1}{ }^{*} U G+\beta_{2}{ }^{*} U E+\beta_{2}{ }^{*} \text { Guide_Bias_Variable }+\Sigma \beta_{c}{ }^{*} \text { Controls }_{c} \\
& +\Sigma \beta_{q}{ }^{*} \text { YearQtr }_{q}+\varepsilon
\end{aligned}
$$

where EA BSI is AMF EA BSI and Total EA BSI in columns (i)-(vi) and (vii)-(ix) of Table 8, respectively. Guide_Bias_Variable (used in columns (i) and (vii)) is the difference between the guidance and the subsequently reported earnings. In columns (ii) to (vi), the Bias_ExtremeY variable is an indicator that is set to 1 when guidance bias is in the most extreme (i.e., the most

\footnotetext{
${ }^{21}$ When we exclude the 2007-2009 financial crisis years, we find that the average market participant does not pull back from trading when there is a higher magnitude of guidance bias. In contrast, AMFs pull back from trading when there is a higher magnitude of guidance bias, both during the crisis and in non-crisis years.
} 
excessively positive) $Y$ decile(s). For example, in column (ii), the indicator variable is set to 1 when the guidance bias is in the top decile. In column (iii), it is set to 1 when guidance bias is in the top two deciles. The sample includes only firm-quarters with bundled guidance. Controls include: MktCap, BTM, and Volatility and are standardized to have a mean (standard deviation) of 0 (1). YearQtr fixed effects are included to remove the effect of any common time trends in abnormal EA buy-sell imbalance during our sample.

The coefficient on Guide_Bias in Table 8 column (i) is negative and insignificant, suggesting no relation between AMFs' buy-sell imbalance and the continuous guidance bias variable. However, when Bias_Extreme1 is used as the bias proxy, we observe a negative and significant coefficient on Bias_Extreme1 (column ii). Evidently, AMFs throttle back their buying when management guidance is extremely optimistically biased (i.e., in the top decile ex post).

We again observe a negative and significant coefficient on Bias_Extreme2 in column (iii), indicating that AMF buying is reliably lower when managerial bias is in the top two deciles. Columns (iv), (v), and (vi) find no significant relation between AMF EA BSI and Bias_Extreme3, Bias_Extreme4, and Bias_Extreme5 (top 3 deciles, top 4 deciles, above median guidance bias, respectively). These results suggest that AMFs can detect optimistic bias in guidance when it is extreme (i.e., in the top quintile of optimistic bias).

In contrast, columns (vii) and (viii) show that the EA buy-sell imbalance for the aggregate market does not have a significant relation with managerial guidance bias. In column (vii), we find an insignificant coefficient on Guide_Bias, and in column (viii) we find an insignificant coefficient on Bias_Extreme. Untabulated analyses find insignificant coefficients on the four additional cutoffs for Bias_Extreme. Our inference is that, while the market may trade less when the magnitude of the managerial bias is high (see Table 7), the typical trader is unable to determine 
the direction of the bias. In contrast, AMFs can detect directional optimistic bias in management forecasts, and adjust their trading accordingly. These results further support the view that AMFs have a greater ability to efficiently process the information in bundled management guidance. ${ }^{22}$

\subsection{Speed of Price Adjustment}

\subsubsection{Return Accumulation in Days [0,+4]}

We examine whether AMF trading in the EA period results in faster price adjustment. Specifically, we test whether the fraction of the $[0,+63]$ return realized in days $[0,+4]$ is greater when the intensity of AMF EA trading is high in the $[0,+4]$ period. We retain only observations with very positive or very negative raw $[0,+63]$ returns, to avoid small denominators. Specifically, we restrict the sample to $[0,+63]$ raw returns that are in the top or bottom quintile, within the year of the EA. CRSP returns are delisting-adjusted, based on Shumway (1997) and Beaver, McNichols, and Price (2007). Table 9, Panel A presents descriptive statistics of firm-quarters with bundled guidance where the $[0,+63]$ returns is also in the top or bottom quintile. Panel B presents results when the fraction of $[0,+63]$ returns that occurs in days $[0,+4]$ is regressed on abnormal volume variables. Controls include: MktCap, BTM, and Volatility and are standardized to have a mean (standard deviation) of 0 (1). YearQtr fixed effects are included to remove the effect of any common time trends in EA price adjustment during our sample.

The dependent variable is Abn AMF EA Volume, AMF Vol as a Frac of Tot Volume, and Concordant AMF EA Trading in columns (i), (ii), and (iii) of Table 9, Panel B, respectively. Concordant AMF EA Trading is an indicator variable set equal to 1 for firm-quarters where the AMF trading and the $U G$ news are directionally concordant. Specifically, Concordant AMF EA

\footnotetext{
${ }^{22}$ In general, we find similar results when we focus on the financial crisis of 2007-2009 and when we exclude these financial crisis years. Under both regimes, AMFs seem to process guidance news more efficiently.
} 
Trading is equal to 1 when AMF EA BSI in the top quintile and $U G$ is also in the top quintile, or when $A M F E A B S I$ in the bottom quintile and $U G$ is also in the bottom quintile. We include the same Controls as those in our previous tests.

In Table 9, Panel B column (i), the coefficient on Abn AMF EA Volume is positive and significant, suggesting that the return accumulation at the EA is faster when AMFs trade more during the EA. Similarly, the coefficient on AMF Vol as a Frac of Tot Volume in column (ii) is positive and significant, indicating that the return accumulation is faster when AMF trading at the EA is a larger proportion of total trading volume at the EA. We do not find evidence that directional trading of AMFs helps to incorporate information into prices more quickly in column (iii). Specifically, we find that when AMFs trade in the same direction as unexpected guidance (i.e., when Concordant AMF EA Trading = 1), the fraction of $[0,+63]$ returns that occurs in days $[0,+4]$ is not significantly higher. We again find similar results when we focus on the financial crisis of 2007-2009 and when we exclude these financial crisis years.

\subsubsection{Drift}

We supplement our tests of return accumulation by examining the impact of AMF trading at the EA on the post-guidance price drift. We first confirm the existence of such a price drift in the incorporation of $U G$ news into returns, for smaller firms' bundled guidance announcements only. To control for firm size and unexpected earnings, we first sort each observation into three $U E$ terciles. Within each of the three $U E$ terciles, we sort each observation into three market cap terciles. Our sample of smaller firms includes those with market cap in the first and second terciles (i.e., we remove firms in the largest tercile). CRSP returns are delisting-adjusted, based on Shumway (1997) and Beaver et al. (2007). For each firm-quarter, we calculate the $[+4,+63]$ return as the post-EA return. These returns are winsorized at the 1st and 99th percentile, by fiscal quarter 
end date. These returns are then size-adjusted, with the market value calculated at the fiscal quarter end date and sorted into deciles based on all other stocks in the CRSP universe at that date. Before calculating the size-decile returns, we winsorize all firms' buy and hold returns in the $[+4,+63]$ window around all dates at the 1st and 99th percentile, by date. We then subtract out the equalweighted average $[+4,+63]$ return, relative to the EA date, of those firms in the size decile to obtain the equal-weighted size-adjusted returns.

Table 10, Panel A presents descriptive statistics for this sample. The following OLS model tests for the existence of a guidance-related drift:

$$
\begin{aligned}
\text { AbnRet }[+4,+63]=\quad & \alpha+\beta_{1} * U G+\beta_{2} * U E+\beta_{3} * A b n \text { EA Tot Volume }+\beta_{4} * \text { AbnRet }[0,+4] \\
& +\Sigma \beta_{c}{ }^{*} \text { Controls }_{c}+\varepsilon
\end{aligned}
$$

We use the same Controls variables as in our prior models, with the addition of $A b n E A$ Tot Volume and AbnRet $[0,+4]$. Future returns may be related to total trading volume or returns at the EA, and we want to account for these variables when assessing the impact of AMF participation at the EA. Column (i) of Table 10, Panel B finds a positive and significant coefficient on $U G$, suggesting that unexpected guidance is incorporated into returns slowly. This positive coefficient is consistent with evidence in $\mathrm{Ng}$ et al. (2013) that the market underreacts to guidance. In untabulated analyses, we find no evidence of guidance drift in large firms (i.e., insignificant coefficient on $U G)$. Consistent with literature that finds that PEAD in recent years has essentially disappeared, we find an insignificant coefficient on UE (Ayers, Li, and Yeung 2011; Dechow, Sloan, and Zha 2014).

After documenting a guidance-related price drift in our sample, we test for the effect of AMF EA trading on this drift, using the following OLS model: 


$$
\begin{aligned}
\text { AbnRet }[+4,+63]= & \alpha+\beta_{1} * U E+\beta_{2} * \text { HighAMFVariable }+\beta_{3} * U G \times \text { HighAMFVariable } \\
& +\beta_{4} * U G \times \text { LowAMFVariable }+\beta_{5} * \text { Abn EA Tot Volume } \\
& +\beta_{6} * \text { AbnRet }[0,+4]+\Sigma \beta_{c}{ }^{*} \text { Controls }_{c}+\varepsilon
\end{aligned}
$$

We use three different empirical proxies to capture a high level of AMF participation during the EA (the HighAMFVariable in the above equation). The first proxy, High Abn AMF EA Volume, is an indicator variable set to 1 when $A b n$ AMF EA Volume is above the median (see column (ii)). ${ }^{23}$ The second proxy, High AMF Vol as a Frac of Tot Volume, is an indicator variable set to 1 when AMF Vol as a Frac of Tot Volume is above the median (see column (iii)). The third proxy, Concordant AMF EA Trading, is an indicator variable set to 1 for firm-quarters with both AMF $E A B S I$ and $U G$ in the top quintile, or both $A M F E A B S I$ and $U G$ in the bottom quintile (see column (iv)). In each of the three instances, we include a LowAMFVariable, which is defined as the ones’ complement of each of the HighAMFVariable variables in their respective columns (e.g., in column ii, the HighAMFVariable is High Abn AMF EA Volume and the LowAMFVariable is Low Abn AMF EA Volume). ${ }^{24}$

Table 10, column (ii) finds an insignificant coefficient on $U G \times$ High Abn AMF EA Volume, suggesting no guidance-related drift when AMF EA trading volume is above median. In contrast, we find a positive and marginally significant coefficient on $U G \times$ Low Abn AMF EA Volume, which

\footnotetext{
${ }^{23}$ To control for firm size and unexpected earnings, we first sort each observation into three $U E$ terciles. Within each of the three $U E$ terciles, we sort each observation into three market cap terciles, forming nine subgroups. We then classify each firm-quarter observation based on its AMF participation variable into above-median and belowmedian categories, within each of the nine subgroups. We do this ranking within subgroups and within year, to mitigate the effect that the magnitude of earnings news and firm liquidity may have on the magnitude of the $U G$ drift.

${ }^{24}$ Specifically, the coefficient on $U G \times$ HighAMFVariable is equivalent to the coefficient on $U G$ when HighAMFVariable $=1$. The coefficient on $U G \times$ LowAMFVariable is equivalent to the coefficient on $U G$ when LowAMFVariable $=1$. We omit the main effect $U G$ from the regression, because it is a linear combination of $U G \times$ HighAMFVariable and $U G \times$ LowAMFVariable. We omit the main effect LowAMFVariable from the regression, because it is a linear combination of 1 and HighAMFVariable (and the regression estimates an intercept $\alpha)$.
} 
provides some evidence of guidance-related drift when AMF EA trading volume is below median. In column (iii), we find no guidance-related drift when AMFs disproportionately participate at the EA, and we also find no guidance-related drift when AMFs participate less relative to the average market participant at the EA. In column (iv), we continue to find results consistent with our Hypothesis 3. When AMFs trade in the same direction as $U G$, there is no evidence of guidancerelated drift. However, when AMFs do not trade in the same direction as $U G$, there is a positive and marginally significant coefficient on $U G \times$ Discordant AMF EA Trading, which is evidence of guidance-related drift. ${ }^{25}$

In sum, our results in Tables 9 and 10 provide evidence generally consistent with the hypothesis that AMFs' trading at the EA facilitates price discovery. The return accumulation in days $[0,+4]$ is greater and the guidance-related drift does not exist, when AMFs participate more at the EA. We obtain consistent results using multiple measures of AMF participation at the EA.

\section{CONCLUSION}

This study has two goals: 1) to evaluate whether AMFs efficiently respond to the information at quarterly EAs, and 2) to understand how AMF actions relate to the price discovery mechanism in the market. Our analysis of 76,939 firm-quarters for 4,435 unique firms finds that AMFs have high trading volume at the EA, especially when there is a concurrent management forecast in $37 \%$ of the firm-quarters.

We document relatively unambiguous evidence of AMF skill in processing EA news, particularly guidance news. When the two main pieces of EA news are directionally inconsistent,

\footnotetext{
${ }^{25}$ When we focus on the financial crisis years of 2007-2009, we do not find evidence of post-guidance price drift. Excluding the financial crisis years from our sample, we find similar results to those presented in Table 10. Postguidance price drift exists in small firms only when AMF EA trading volume is low and when AMFs do not trade in the same direction as $U G$.
} 
AMFs focus on guidance news rather than earnings news. Further, they appear able to detect guidance bias and adjust their trading accordingly. Our focus on AMFs, excluding hedge funds, is important because prior studies have distinguished the two groups from each other in terms of their skill levels, sometimes referring to hedge funds as "smart money" and other AMFs as "dumb money” (Ha and Hu 2018). ${ }^{26}$ Our study shows that AMFs possess an informational advantage, relative to the average market participant, in the processing of relevant news at the EA. At the same time, we address the need for more trade-level evidence in accounting research when studying the market response to corporate events (Hu et al. 2018).

Our results also speak to the broader issue of market efficiency. Specifically, we find that AMFs play a significant role in facilitating the integration of EA information into price. Using multiple tests, we show that increased AMF trading leads to a faster and more complete price adjustment process in relation to guidance news. These findings extend the literature on price underreaction by directly linking the magnitude of the price drift to the amount of EA intervention by AMFs. In addition, our results on the effect of directional AMF trading among small firms suggest that the persistence of the drift could be due to elevated arbitrage costs, which can limit AMF involvement among these stocks.

Previous literature has found that the short window around EAs is a period of "correction" to stock prices, as a substantial fraction of the abnormal returns to various strategies are realized in the days around the EA (Sloan 1996; Jegadeesh and Titman 1993; La Porta et al. 1997; Engelberg et al. 2018). We contribute to this literature by showing that AMF trading in this short window facilitates the convergence of stock prices to fundamental value. Specifically, we find that both the level and the direction of AMF trades at the EA are associated with increased speed

\footnotetext{
${ }^{26}$ Another study that finds skill in hedge funds is Agarwal, Jiang, Tang and Yang (2013). The study finds that the confidential filings of hedge funds exhibit superior performance and are consistent with private information.
} 
of price adjustment and reduced post-guidance price drift.

Finally, our findings contribute to the longstanding literature on AMF performance. Most prior studies on AMF, and particularly MF, performance conclude that they dramatically underperform. However, these results are difficult to reconcile with costly information acquisition and the continued existence of a large active management industry (Ippolito 1989; Berk and Green 2004). Two possible reasons for the documented underperformance of AMFs are: (a) investor flows (Edelen 1999), and (b) lack of power (Kothari and Warner 2001). We address these problems using an event study approach, highly granular trade-level data, and specific earnings releases that require some unbundling. ${ }^{27}$

Our evidence shows that AMFs possess significant skill in incorporating EA information into prices. They are particularly skilled in interpreting management guidance, which may be biased by firms’ strategic disclosure behavior. Our findings suggest professional active managers who run individual investors’ money may be important agents in the market price discovery process. These findings seem particularly noteworthy as the move from active to passive asset management continues to gain prominence. Our results show active managers enhance price discovery within the context of earnings releases. Clearly, further research on the skill of active managers and their effects on the market in other settings will be necessary to help round out the picture.

\footnotetext{
${ }^{27}$ Other papers have also used trade-level data to infer the skill of institutional investors (e.g., Gallagher, Looi, and Pinnuck 2010; von Beschwitz, Lunghi, and Schmidt 2017; Huang et al. 2016; Di Mascio, Lines, and Naik 2017). Our study is unique in that we link trade-level AMF data to specific news items released during a bundled EA period.
} 


\section{REFERENCES}

Agarwal, V., W. Jiang, Y. Tang, and B. Yang. 2013. Uncovering hedge fund skill from the portfolio holdings they hide. The Journal of Finance 68(2): 739-783.

Anilowski, C., Feng, M. and Skinner, D.J. 2007. Does earnings guidance affect market returns? The nature and information content of aggregate earnings guidance. Journal of Accounting and Economics 44(1-2): 36-63.

Arif, S., A. Ben-Rephael, and C. Lee. 2017. Mutual Funds and Short-Sellers: Why Does ShortSale Volume Predict Stock Returns? Working paper. Indiana University and Stanford University. February 24.

Atiase, R.K., Li, H., Supattarakul, S. and Tse, S. 2005. Market reaction to multiple contemporaneous earnings signals: Earnings announcements and future earnings guidance. Review of Accounting Studies 10(4): 497-525.

Ayers, B.C., Li, O.Z. and Yeung, P.E. 2011. Investor trading and the post-earningsannouncement drift. The Accounting Review 86(2): 385-416.

Baginski, S.P., Campbell, J.L., Ryu, P. and Warren, J. 2019. Do Managers Bias their Forecasts of Future Earnings in Response to their Firm's Current Earnings Announcement Surprises?. Working Paper. July 18.

Baker, M., L. Litov, J. A. Wachter, and J. Wurgler. 2010. Can mutual fund managers pick stocks? Evidence from their trades prior to earnings announcements. Journal of Financial and Quantitative Analysis 45(5): 1111-1131.

Ball, R., and P. Brown. 1968. An empirical evaluation of accounting income numbers. Journal of Accounting Research 6(2): 159-178.

Ball, R. and Shivakumar, L. 2008. How much new information is there in earnings?. Journal of Accounting Research 46(5): 975-1016.

Barber, B. M., Y. T. Lee, Y. J. Liu, and T. Odean. 2009a. Just how much do individual investors lose by trading? The Review of Financial Studies 22(2): 609-632.

Barber, B. M., and T. Odean. 2000. Trading is hazardous to your wealth: The common stock investment performance of individual investors. The Journal of Finance 55(2): 773-806.

Barber, B. M., and T. Odean. 2008. All that glitters: The effect of attention and news on the buying behavior of individual and institutional investors. The Review of Financial Studies 21(2): 785-818. 
Barber, B. M., T. Odean, and N. Zhu. 2009b. Systematic noise. Journal of Financial Markets 12(4): 547-569.

Bartov, E., S. Radhakrishnan, and I. Krinsky. 2000. Investor sophistication and patterns in stock returns after earnings announcements. The Accounting Review 75(1): 43-63.

Battalio, R. H., and R. R. Mendenhall. 2005. Earnings expectations, investor trade size, and anomalous returns around earnings announcements. Journal of Financial Economics 77(2): 289319.

Beaver, W. H. 1968. The information content of annual earnings announcements. Journal of Accounting Research 6: 67-92.

Beaver, W., M. McNichols, and R. Price. 2007. Delisting returns and their effect on accountingbased market anomalies. Journal of Accounting and Economics 43(2): 341-368.

Ben-Rephael, A., Z. Da, and R. D. Israelsen. 2017. It Depends on Where You Search: Institutional Investor Attention and Underreaction to News. The Review of Financial Studies 30(9): 3009-3047.

Berk, J. B., and R. C. Green. 2004. Mutual fund flows and performance in rational markets. Journal of Political Economy 112(6): 1269-1295.

Beyer, A., Cohen, D.A., Lys, T.Z. and Walther, B.R. 2010. The financial reporting environment: Review of the recent literature. Journal of Accounting and Economics 50(2-3): 296-343.

Bhattacharya, N. 2001. Investors' trade size and trading responses around earnings announcements: An empirical investigation. The Accounting Review 76(2): 221-244.

Billings, M.B., Jennings, R. and Lev, B. 2015. On guidance and volatility. Journal of Accounting and Economics 60(2-3): 161-180.

Blankespoor, E., deHaan, E., Wertz, J. and Zhu, C. 2019. Why do individual investors disregard accounting information? The roles of information awareness and acquisition costs. Journal of Accounting Research 57(1): 53-84.

Bliss, B.A., Partnoy, F., and Furchtgott, M. 2018. Information bundling and securities litigation. Journal of Accounting and Econoomics 65(1): 61-84.

Brown, S., Hillegeist, S.A. and Lo, K. 2009. The effect of earnings surprises on information asymmetry. Journal of Accounting and Economics 47(3): 208-225.

Carhart, M. M. 1997. On persistence in mutual fund performance. The Journal of Finance 52(1): 57-82. 
Chen, L.H., Huang, W. and Jiang, G.J., 2019. Do Mutual Funds Trade on Earnings News? The Information Content of Large Active Trades. Working paper. February 18.

Cheng, S., A. Hameed, A. Subrahmanyam, and S. Titman. 2017. Short-Term Reversals: The Effects of Past Returns and Institutional Exits. Journal of Financial and Quantitative Analysis 52(1): 143-173.

Cheng, Q. and Lo, K. 2006. Insider trading and voluntary disclosures. Journal of Accounting Research 44(5): 815-848.

Cheng, Q., Luo, T. and Yue, H. 2013. Managerial incentives and management forecast precision. The Accounting Review 88(5): 1575-1602.

Choi, J.H., Myers, L.A., Zang, Y. and Ziebart, D.A. 2011. Do management EPS forecasts allow returns to reflect future earnings? Implications for the continuation of management's quarterly earnings guidance. Review of Accounting Studies 16(1): 143-182.

Collins, D. W., G. Gong, and P. Hribar. 2003. Investor sophistication and the mispricing of accruals. Review of Accounting Studies 8(2): 251-276.

Coval, J., and E. Stafford. 2007. Asset fire sales (and purchases) in equity markets. Journal of Financial Economics 86(2): 479-512.

Cready, W., A. Kumas, and M. Subasi. 2014. Are trade Size-Based inferences about traders reliable? evidence from institutional Earnings-Related trading. Journal of Accounting Research 52(4): 877-909.

Da, Z., J. Engelberg, and P. Gao. 2011. In search of attention. The Journal of Finance 66(5): 1461-1499.

Daniel, K., M. Grinblatt, S. Titman, and R. Wermers. 1997. Measuring mutual fund performance with characteristic-based benchmarks. The Journal of Finance 52(3): 1035-1058.

Dechow, P. M., R. G. Sloan, and J. Zha. 2014. Stock prices and earnings: A history of research. Annual Review of Financial Economics 6(1): 343-363.

deHaan, E., T. Shevlin, and J. Thornock. 2015. Market (in) attention and the strategic scheduling and timing of earnings announcements. Journal of Accounting and Economics 60(1): 36-55.

Di Mascio, R., A. Lines, and N. Y. Naik. 2017. Alpha Decay. Working Paper. November 21.

Easley, D., López de Prado, M. and O’Hara, M. 2012. Bulk classification of trading activity. Working Paper. March.

Edelen, R. M. 1999. Investor flows and the assessed performance of open-end mutual funds. Journal of Financial Economics 53(3): 439-466. 
Edelen, R. M., O. S. Ince, and G. B. Kadlec. 2016. Institutional investors and stock return anomalies. Journal of Financial Economics 119(3): 472-488.

El-Gazzar, S. M. 1998. Predisclosure information and institutional ownership: A cross-sectional examination of market revaluations during earnings announcement periods. The Accounting Review 73(1): 119-129.

Engelberg, J., R. D. McLean, and J. Pontiff. 2018. Anomalies and News. The Journal of Finance 73(5): 1971-2001.

Fama, E. F., and K. R. French. 2010. Luck versus skill in the cross-section of mutual fund returns. The Journal of Finance 65(5): 1915-1947.

Frazzini, A., and O. A. Lamont. 2008. Dumb money: Mutual fund flows and the cross-section of stock returns. Journal of Financial Economics 88(2): 299-322.

French, K. R. 2008. Presidential address: The cost of active investing. The Journal of Finance 63(4): 1537-1573.

Gallagher, D. R., Looi, A., and M. Pinnuck. 2010. Are active fund managers collectors of private information or fast interpreters of public information?. Accounting \& Finance, 50(3): 635-662.

Gong, G., Li, L.Y. and Wang, J.J. 2011. Serial correlation in management earnings forecast errors. Journal of Accounting Research 49(3): 677-720.

Gong, G., Li, L.Y. and Xie, H. 2009. The association between management earnings forecast errors and accruals. The Accounting Review 84(2): 497-530.

Goodman, T.H., Neamtiu, M., Shroff, N. and White, H.D. 2014. Management forecast quality and capital investment decisions. The Accounting Review 89(1): 331-365.

Grinblatt, M., and S. Titman. 1994. A study of monthly mutual fund returns and performance evaluation techniques. Journal of Financial and Quantitative Analysis 29(3): 419-444.

Ha, J., and J. Hu. 2018. How Smart is Institutional Trading? Working paper. Singapore Management University. January 15.

Hilary, G. and Hsu, C. 2011. Endogenous overconfidence in managerial forecasts. Journal of Accounting and Economics 51(3): 300-313.

Hilary, G., Hsu, C. and Wang, R. 2014. Management forecast consistency. Journal of Accounting Research 52(1): 163-191.

Hou, K., Xiong, W. and Peng, L. 2009. A tale of two anomalies: The implications of investor attention for price and earnings momentum. Working Paper. January 16. 
Hu, G., K. Jo, Y. A. Wang, and J. Xie. 2018. Institutional Trading and Abel Noser Data. Journal of Corporate Finance 52: 143-167.

Hu, G., B. Ke, and Y. Yu. 2018. Can Transient Institutions Correctly Interpret Small Negative Earnings Surprises in the Absence of Access to Management's Private Information?. Journal of Accounting, Auditing and Finance 33(1): 3-33.

Ippolito, R. A. 1989. Efficiency with costly information: A study of mutual fund performance, 1965-1984. The Quarterly Journal of Economics 104(1): 1-23.

Jame, R. 2018. Liquidity Provision and the Cross Section of Hedge Fund Returns. Management Science (forthcoming).

Jegadeesh, N., and S. Titman. 1993. Returns to buying winners and selling losers: Implications for stock market efficiency. The Journal of Finance 48(1): 65-91.

Jensen, M. C. 1968. The performance of mutual funds in the period 1945-1964. The Journal of Finance 23(2): 389-416.

Jiambalvo, J., S. Rajgopal, and M. Venkatachalam. 2002. Institutional ownership and the extent to which stock prices reflect future earnings. Contemporary Accounting Research 19(1): 117145.

Jiang, H. and Zheng, L. 2018. Active fundamental performance. The Review of Financial Studies 31(12): 4688-4719.

Johnson, T.L. and So, E.C. 2018. A simple multimarket measure of information asymmetry. Management Science 64(3): 1055-1080.

Kalay, A. 2015. Investor sophistication and disclosure clienteles. Review of Accounting Studies 20(2): 976-1011.

Kato, K., Skinner, D.J. and Kunimura, M. 2009. Management forecasts in Japan: An empirical study of forecasts that are effectively mandated. The Accounting Review 84(5): 1575-1606.

Ke, B. and Ramalingegowda, S. 2005. Do institutional investors exploit the post-earnings announcement drift?. Journal of Accounting and Economics 39(1): 25-53.

Keim, D.B. and Madhavan, A. 1997. Transactions costs and investment style: an inter-exchange analysis of institutional equity trades. Journal of Financial Economics 46(3): 265-292.

Kothari, S. P., and J. B. Warner. 2001. Evaluating mutual fund performance. The Journal of Finance 56(5): 1985-2010. 
Kross, W.J., Ro, B.T. and Suk, I. 2011. Consistency in meeting or beating earnings expectations and management earnings forecasts. Journal of Accounting and Economics 51(1-2): 37-57.

La Porta, R., J. Lakonishok, A. Shleifer, and R. Vishny. 1997. Good news for value stocks: Further evidence on market efficiency. The Journal of Finance 52(2): 859-874.

Lakonishok, J., A. Shleifer, and R. W. Vishny. 1994. Contrarian investment, extrapolation, and risk. The Journal of Finance 49(5): 1541-1578.

Lee, C. M. and Ready, M. J. 1991. Inferring trade direction from intraday data. The Journal of Finance 46(2): 733-746.

Lehman, B. N. and Modest, D. M. 1987. Mutual fund performance evaluation: A comparison of benchmarks and benchmark comparisons. The Journal of Finance 42(2): 233-265.

Lewellen, J. 2011. Institutional investors and the limits of arbitrage. Journal of Financial Economics 102(1): 62-80.

Lou, D. 2012. A flow-based explanation for return predictability. Review of Financial Studies 25(12): 3457-3489.

Malkiel, B.G. 1995. Returns from investing in equity mutual funds 1971 to 1991. The Journal of Finance 50(2): 549-572.

Merton, R.C. 1987. A simple model of capital market equilibrium with incomplete information. The Journal of Finance 42(3): 483-510.

Ng, J., Tuna, I. and Verdi, R. 2013. Management forecast credibility and underreaction to news. Review of Accounting Studies 18(4): 956-986.

PricewaterhouseCoopers. 2017. Active and Wealth Management Insights - Asset Management 2020: Taking Stock. Research study. PwC Asset Management Group. June.

Puckett, A., and X. S. Yan. 2011. The interim trading skills of institutional investors. The Journal of Finance 66(2): 601-633.

Rogers, J.L. and Stocken, P.C. 2005. Credibility of management forecasts. The Accounting Review 80(4): 1233-1260.

Rogers, J.L. and Van Buskirk, A. 2013. Bundled forecasts in empirical accounting research. Journal of Accounting and Economics 55(1): 43-65.

Segal, B. and Segal, D., 2016. Are managers strategic in reporting non-earnings news? Evidence on timing and news bundling. Review of Accounting Studies 21(4): 1203-1244.

Shumway, T. 1997. The delisting bias in CRSP data. The Journal of Finance 52(1): 327-340. 
Sloan, R. 1996. Do stock prices fully reflect information in accruals and cash flows about future earnings? The Accounting Review 71(3): 289-315.

Utama, S., and W. M. Cready. 1997. Institutional ownership, differential predisclosure precision and trading volume at announcement dates. Journal of Accounting and Economics 24(2): 129150 .

von Beschwitz, B., S. Lunghi, and D. Schmidt. 2017. Limits of Arbitrage under the Microscope: Evidence from Detailed Hedge Fund Transaction Data. Working paper. August 10.

Waymire, G. 1984. Additional evidence on the information content of management earnings forecasts. Journal of Accounting Research 22(2): 703-718.

Xu, W. 2010. Do management earnings forecasts incorporate information in accruals?. Journal of Accounting and Economics 49(3): 227-246.

Yang, H.I. 2012. Capital market consequences of managers' voluntary disclosure styles. Journal of Accounting and Economics 53(1-2): 167-184.

Zhang, L. 2012. The effect of ex ante management forecast accuracy on the post-earningsannouncement drift. The Accounting Review 87(5): 1791-1818. 


\section{APPENDIX A: VARIABLE DEFINITIONS}

Variable Name

$[0,+4]$ Ret as a Fraction of $[0,+63]$

Ret

Abn AMF EA Volume

Abn EA Tot Volume

AbnRet $[+4,+63]$

AbnRet $[0,+4]$

Abs_Guide_Bias

Abs_UE

Abs_UG

AMF EA BSI

AMF EA Vol as a Frac of Tot Volume
Description

Source

Fraction of total post-EA $[0,+63]$ returns that accumulates in the first 5 days, calculated as the buy-and-hold raw return on days $[0,+4]$ of the EA scaled by the buy-and-hold raw return on days $[0,+63]$ of the EA.

Average daily AMF volume on days $[0,+4]$ divided by average daily total volume on days [-20,-2].

Average daily total volume on days $[0,+4]$ divided by average daily total volume on days [-20,-2].

Size-adjusted buy-and-hold abnormal return on days $[+4,+63]$ of the EA, where the size adjustment is the equal-weighted $[+4,+63]$ buy-and-hold return for stocks in the size decile, calculated using market cap as of the end of the month of the most recent fiscal quarter end

Size-adjusted buy-and-hold abnormal return on days $[0,+4]$ of the EA, where the size adjustment is the equal-weighted $[0,+4]$ buy-and-hold return for stocks in the size decile, calculated using market cap as of the end of the month of the most recent fiscal quarter end

Absolute value of the bias in management guidance, calculated as the absolute value of the difference between annual guidance for EPS and the realized annual EPS, scaled by price at the most recent fiscal quarter end. If annual guidance for EPS is unavailable, then calculated as the absolute value of the difference between quarterly guidance for EPS and the realized quarterly EPS, scaled by price at the most recent fiscal quarter end.

Absolute value of unexpected earnings, calculated as the absolute value of actual EPS less the median analyst EPS forecast, scaled by price at the most recent fiscal quarter end.

Absolute value of unexpected guidance, calculated as the absolute value of the difference between annual guidance for EPS and the median analyst EPS forecast for the year for which management provides guidance, scaled by price at the most recent fiscal quarter end and adjusted for the current earnings news, following the conditional forecast news measure in Rogers and Van Buskirk (2013). If annual guidance for EPS is unavailable, then we use quarterly guidance for EPS and the median analyst EPS forecast for the quarter for which management provides guidance.

Buy-sell imbalance of AMF trades on days $[0,+4]$ of the EA, calculated as AMF buys in that window minus AMF sells in that window, scaled by all AMF buys and sells in that window. Set to 0 if there are no AMF trades in that window.

Average daily AMF volume as a fraction of total volume, measured on days $[0,+4]$ of the EA.
CRSP

Ancerno, CRSP

CRSP

Compustat, CRSP

Compustat, CRSP

IBES, CRSP

IBES, CRSP

IBES, CRSP

Ancerno

Ancerno, CRSP 
Bias_ExtremeY

BTM

Concordant AMF EA Trading

ConcurrentGuidance

Discordant AMF EA Trading

EarnLoss

GuidanceLoss

Guide_Bias

High Abn AMF EA Volume

High AMF Vol as a Frac of Tot Volume

Inconsistent

Low Abn AMF EA Volume

Low AMF Vol as a Frac of Tot Volume

MktCap
Indicator variable set to 1 if the within-year ranking of Guide_Bias is in the top $Y$ decile(s). The ranking of Guide_Bias is done separately for annual guidance and quarterly guidance, then combined (using annual guidance when available and quarterly guidance when annual guidance is unavailable).

Book-to-market ratio, calculated as of the most recent fiscal year end at "date." The book-to-market ratio is Compustat AT divided by the sum of market value of equity (PRCC_F*CSHO) and the book value of debt (AT - CEQ)

Indicator variable set to 1 if either: 1) $A M F E A B S I$ is in the top quintile and $U G$ is in the top quintile, or 2) AMF EA BSI is in the bottom quintile and $U G$ is in the bottom quintile. Quintile rankings are done within year, and the ranking of $U G$ is done separately for annual guidance and quarterly guidance, then combined (using annual guidance when available and quarterly guidance when annual guidance is unavailable).

Indicator variable set to 1 if management issues a forecast on days $[0,+2]$ of the EA.

The ones' complement of Concordant AMF EA Trading. Specifically, an indicator variable for non-concordant trading, or 1 - Concordant AMF EA Trading.

Indicator variable set to 1 if current earnings are negative.

Indicator variable set to 1 if the management forecasts a loss in the future, whether it is a future quarter or future year, in the bundled guidance.

Bias in management guidance, calculated as the difference between annual guidance for EPS and the realized annual EPS, scaled by price at the most recent fiscal quarter end. If annual guidance for EPS is unavailable, then calculated as the difference between quarterly guidance for EPS and the realized quarterly EPS, scaled by price at the most recent fiscal quarter end.

Indicator variable set to 1 if $A b n$ AMF EA Volume is above the median.

Indicator variable set to 1 if $A M F$ Vol as a Frac of Tot Volume is above the median.

Indicator variable set to 1 if $U G$ is positive and $U E$ is negative, or if $U G$ is negative and $U E$ is positive. If either the quarterly guidance news or the annual guidance news is positive (negative), then $U G$ is considered to be positive (negative) for the purpose of the calculation of this variable.

The ones' complement of High Abn AMF EA Volume. Specifically, below median Abn AMF EA Volume, or 1 - High Abn AMF EA Volume.

The ones' complement of High AMF Vol as a Frac of Tot Volume. Specifically, below median AMF Vol as a Frac of Tot Volume, or 1 - High AMF Vol as a Frac of Tot Volume.

Market cap as of the most recent fiscal quarter end.
IBES, CRSP

Compustat

Ancerno, IBES

IBES

Ancerno, IBES

Compustat

IBES

IBES, CRSP

Ancerno, CRSP

Ancerno, CRSP

IBES, CRSP

Ancerno, CRSP

Ancerno, CRSP

CRSP 
Buy-sell imbalance of all trades on days $[0,+4]$ of the EA, calculated as total buy-initiated volume in that window minus total sell-initiated volume in that window, scaled by all buys and sells in that window. Set to 0 if there are no trades in that window. Each trade is classified as a buy or a sell based on the Lee and Ready (1991) tick test.

$U E$

Unexpected earnings, calculated as the actual EPS less the median analyst IBES, CRSP EPS forecast, scaled by price at the most recent fiscal quarter end.

Unexpected guidance, calculated as the annual guidance for EPS and the median analyst EPS forecast for the year for which management provides guidance, scaled by price at the most recent fiscal quarter end and adjusted $U G$ for the current earnings news, following the conditional forecast news measure in Rogers and Van Buskirk (2013). If annual guidance for EPS is IBES, CRSP unavailable, then we use quarterly guidance for EPS and the median analyst EPS forecast for the quarter for which management provides guidance.

Stock return volatility, annualized and calculated as the standard deviation of log of 1 plus daily stock returns over days [-102,-2] relative to the EA. 


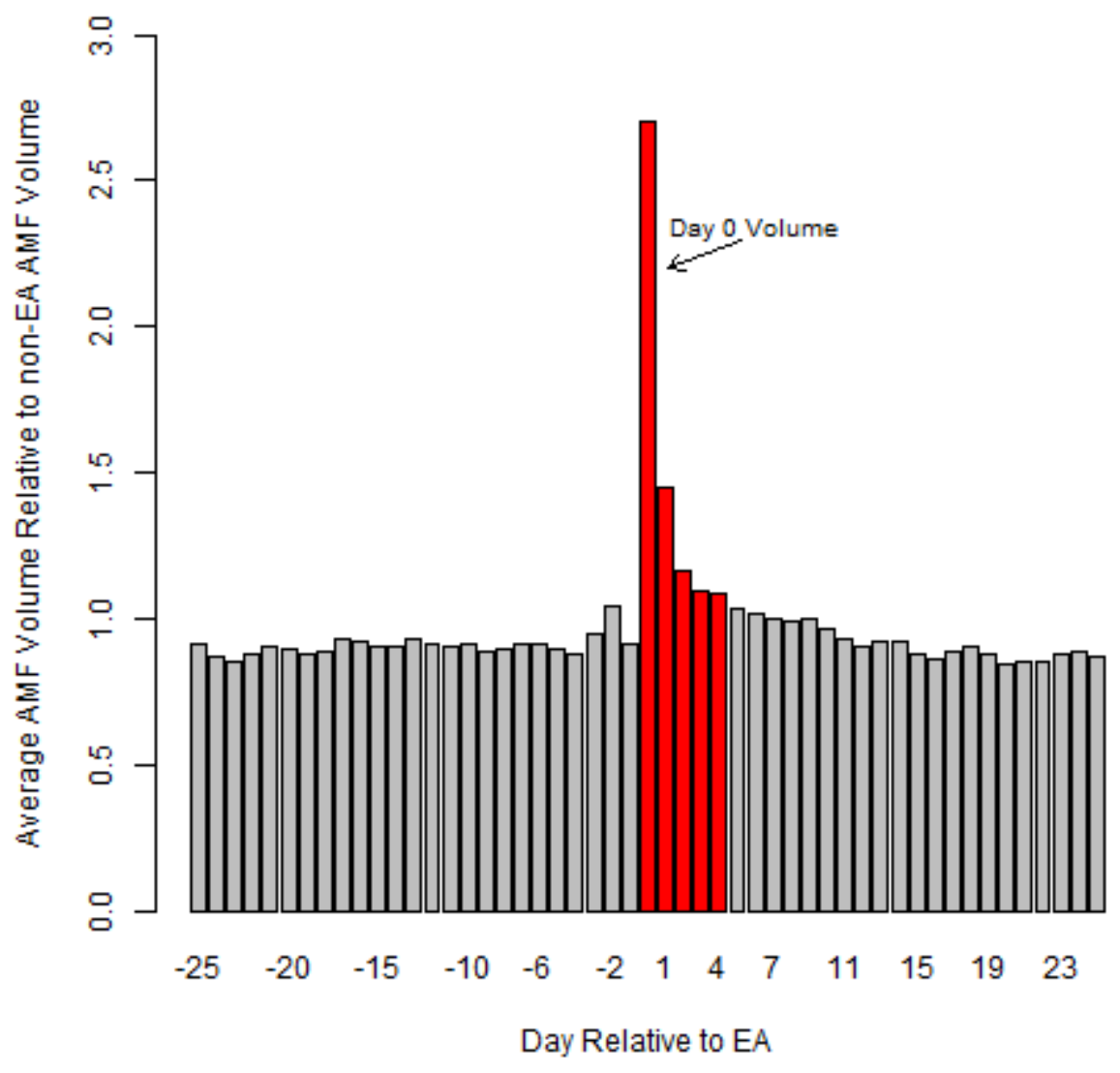

This figure presents the abnormal trading volume by actively managed funds (AMFs) in the 51 trading days centered around quarterly earnings announcements (EAs). Abnormal trading volume is defined as the average daily trading volume by AMFs, scaled by the average daily AMF trading volume during non-announcement days. We compute average abnormal trading volume for each firm-quarter and graph the average over all firm-quarters in our sample. The time period covered is 2003 to 2010 . 


\section{Table 1: Descriptive Statistics}

This table presents descriptive statistics for untransformed variables. All variables are defined in Appendix A.

\begin{tabular}{|c|c|c|c|c|c|c|c|c|}
\hline & $\mathrm{N}$ & Mean & Std Dev & $\mathrm{P} 1$ & P25 & Median & P75 & P99 \\
\hline \multicolumn{9}{|l|}{ AMF Volume Variables } \\
\hline Day 0 AMF Volume & 76,939 & $100,713.32$ & $386,849.14$ & 0.00 & 0.00 & $5,032.00$ & $60,424.00$ & $1,483,370.24$ \\
\hline Day 1 AMF Volume & 76,939 & $55,281.40$ & $222,997.22$ & 0.00 & 0.00 & $1,683.00$ & $29,200.00$ & $854,783.56$ \\
\hline Day 2 AMF Volume & 76,939 & $44,603.34$ & $200,109.57$ & 0.00 & 0.00 & $1,250.00$ & $23,330.00$ & $673,861.22$ \\
\hline Day 3 AMF Volume & 76,939 & $41,679.28$ & $171,779.86$ & 0.00 & 0.00 & $1,200.00$ & $21,800.00$ & $647,805.66$ \\
\hline Day 4 AMF Volume & 76,939 & $41,032.85$ & $162,242.26$ & 0.00 & 0.00 & $1,100.00$ & $20,892.50$ & $644,778.46$ \\
\hline \multicolumn{9}{|l|}{ EA Volume Variables } \\
\hline AMF Average EA $[0,+4]$ Daily Volume & 76,939 & $56,662.04$ & $172,040.33$ & 0.00 & 992.20 & $10,953.80$ & $46,957.40$ & $689,179.08$ \\
\hline Total Average EA $[0,+4]$ Daily Volume & 76,939 & $2,280,926.74$ & $10,190,625.58$ & $11,443.59$ & $231,286.90$ & $650,323.40$ & $1,852,293.40$ & $25,421,464.00$ \\
\hline \multicolumn{9}{|l|}{$\underline{\text { Non-EA Volume Variables }}$} \\
\hline AMF Average [-20,-2] Daily Volume & 76,939 & $35,161.83$ & $94,510.86$ & 0.00 & $1,790.26$ & $9,181.42$ & $31,638.21$ & $406,641.86$ \\
\hline Total Average [-20,-2] Daily Volume & 76,939 & $1,517,170.44$ & $6,974,973.40$ & $10,244.84$ & $143,566.95$ & $391,477.84$ & $1,141,162.32$ & $17,696,862.21$ \\
\hline \multicolumn{9}{|l|}{ Firm-Quarter Variables, Full Sample } \\
\hline Abn AMF EA Volume & 76,939 & 0.07 & 0.16 & 0.00 & 0.00 & 0.02 & 0.08 & 0.69 \\
\hline Abn EA Tot Volume & 76,939 & 1.80 & 1.32 & 0.48 & 1.13 & 1.50 & 2.07 & 6.54 \\
\hline AMF EA Vol as a Frac of Tot Volume & 76,939 & 0.03 & 0.05 & 0.00 & 0.00 & 0.02 & 0.04 & 0.25 \\
\hline ConcurrentGuidance & 76,939 & 0.37 & 0.48 & 0.00 & 0.00 & 0.00 & 1.00 & 1.00 \\
\hline Abs_UE & 76,939 & 0.01 & 0.04 & 0.00 & 0.00 & 0.00 & 0.00 & 0.06 \\
\hline EarnLoss & 76,939 & 0.18 & 0.38 & 0.00 & 0.00 & 0.00 & 0.00 & 1.00 \\
\hline GuidanceLoss & 76,939 & 0.01 & 0.12 & 0.00 & 0.00 & 0.00 & 0.00 & 1.00 \\
\hline MktCap & 76,939 & $5,298.62$ & $18,865.43$ & 154.26 & 410.91 & $1,025.91$ & $3,006.15$ & $78,969.48$ \\
\hline BTM & 76,939 & 0.64 & 0.27 & 0.13 & 0.43 & 0.65 & 0.87 & 1.19 \\
\hline Volatility & 76,939 & 0.03 & 0.01 & 0.01 & 0.02 & 0.02 & 0.03 & 0.08 \\
\hline \multicolumn{9}{|c|}{ Firm-Quarter Variables, Bundled Guidance Sample } \\
\hline Abn AMF EA Volume & 28,731 & 0.08 & 0.15 & 0.00 & 0.01 & 0.04 & 0.09 & 0.68 \\
\hline Abn EA Tot Volume & 28,731 & 1.88 & 1.12 & 0.60 & 1.22 & 1.60 & 2.19 & 6.19 \\
\hline AMF EA Vol as a Frac of Tot Volume & 28,731 & 0.04 & 0.05 & 0.00 & 0.01 & 0.02 & 0.05 & 0.25 \\
\hline AMF EA BSI & 28,731 & 0.01 & 0.72 & -1.00 & -0.71 & 0.00 & 0.74 & 1.00 \\
\hline Total EA BSI & 28,731 & 0.02 & 0.08 & -0.20 & -0.02 & 0.00 & 0.05 & 0.27 \\
\hline Abs_UG & 28,731 & 0.01 & 0.36 & 0.00 & 0.00 & 0.00 & 0.00 & 0.05 \\
\hline Abs_UE & 28,731 & 0.00 & 0.02 & 0.00 & 0.00 & 0.00 & 0.00 & 0.02 \\
\hline Abs_Guide_Bias & 28,731 & 0.02 & 0.39 & 0.00 & 0.00 & 0.00 & 0.01 & 0.21 \\
\hline$U G$ & 28,731 & 0.00 & 0.36 & -0.04 & 0.00 & 0.00 & 0.00 & 0.02 \\
\hline$U E$ & 28,731 & 0.00 & 0.02 & -0.01 & 0.00 & 0.00 & 0.00 & 0.01 \\
\hline Guide_Bias & 28,731 & 0.01 & 0.39 & -0.04 & 0.00 & 0.00 & 0.00 & 0.20 \\
\hline EarnLoss & 28,731 & 0.11 & 0.31 & 0.00 & 0.00 & 0.00 & 0.00 & 1.00 \\
\hline GuidanceLoss & 28,731 & 0.04 & 0.19 & 0.00 & 0.00 & 0.00 & 0.00 & 1.00 \\
\hline MktCap & 28,731 & $6,588.27$ & $20,879.94$ & 168.13 & 621.27 & $1,544.46$ & $4,161.34$ & $87,994.50$ \\
\hline BTM & 28,731 & 0.60 & 0.24 & 0.14 & 0.41 & 0.58 & 0.78 & 1.14 \\
\hline Volatility & 28,731 & 0.02 & 0.01 & 0.01 & 0.02 & 0.02 & 0.03 & 0.06 \\
\hline
\end{tabular}




\section{Table 2: Analysis of Volume and Concurrent Guidance}

This table presents the results of regressing Abn AMF EA Volume, Abn EA Tot Volume, and AMF Vol as a Frac of Tot Volume on an indicator variable for management guidance concurrent with the EA and the absolute value of unexpected earnings. We measure unexpected earnings relative to the IBES consensus forecast. Controls include: MktCap, BTM, and Volatility, each of which has been standardized to have a mean (standard deviation) of 0 (1). Fiscal year-quarter fixed effects are included in all models. Standard errors are clustered by firm and EA date. All variables are defined in Appendix A. T-statistics are in parentheses. *** indicates significance at $1 \%$; ** at $5 \%$; and * at $10 \%$.

\begin{tabular}{lccc}
\hline & \multicolumn{3}{c}{ Dependent variable: } \\
\cline { 2 - 4 } & & & AMF Vol as a Frac of \\
& Abn AMF EA Volume & Abn EA Tot Volume & Tot Volume \\
\cline { 2 - 4 } ConcurrentGuidance & $(\mathrm{i})$ & $(\mathrm{ii})$ & $(\mathrm{iii})$ \\
& $0.015^{* * *}$ & $0.158^{* * *}$ & $0.006^{* * *}$ \\
Abs_UE & $(10.23)$ & $(12.05)$ & $(8.98)$ \\
& $0.368^{*}$ & $13.660^{* * *}$ & $-0.108^{* * *}$ \\
EarnLoss & $(1.65)$ & $(8.09)$ & $(-3.75)$ \\
& $-0.013^{* * *}$ & $-0.153^{* * *}$ & $-0.005^{* * *}$ \\
GuidanceLoss & $(-5.60)$ & $(-8.61)$ & $(-5.23)$ \\
& $-0.008^{*}$ & 0.051 & $-0.004^{* *}$ \\
MktCap & $(-1.75)$ & $(1.18)$ & $(-2.28)$ \\
& $-0.010^{* * *}$ & $-0.104^{* * *}$ & $-0.003^{* * *}$ \\
BTM & $(-17.86)$ & $(-16.71)$ & $(-12.30)$ \\
& $-0.003^{* * *}$ & $-0.106^{* * *}$ & $0.001^{* * *}$ \\
Volatility & $(-4.01)$ & $(-15.01)$ & $(3.08)$ \\
& $-0.008^{* * *}$ & $-0.022^{* * *}$ & $-0.004^{* * *}$ \\
Firm and Date Clustered & $(-8.85)$ & $(-3.03)$ & $(-11.74)$ \\
SEs & & & \\
Qtr Fixed Effects & Yes & Yes & Yes \\
Observations & Yes & Yes & Yes \\
R2 & 76,939 & 76,939 & 76,939 \\
& 0.036 & 0.053 & 0.038
\end{tabular}




\section{Table 3: Analysis of Bundled Guidance Earnings Announcements}

This table presents results of regressing Abn AMF EA Volume, Abn EA Tot Volume, and AMF Vol as a Frac of Tot Volume on the absolute value of unexpected guidance (Abs_UG) and the absolute value of unexpected earnings (Abs_UE). Unexpected earnings is computed relative to the IBES Consensus forecast. Unexpected guidance news is calculated using the conditional expectations model based on the current period unexpected earnings (Rogers and Van Buskirk 2013). The sample includes only firm-quarters with bundled guidance. Controls include: MktCap, BTM, and Volatility and are standardized to have a mean (standard deviation) of 0 (1). Fiscal year-quarter fixed effects are included in all models. Standard errors are clustered by firm and EA date. All variables are defined in Appendix A. T-statistics are in parentheses. *** indicates significance at $1 \%$; ** at 5\%; and * at $10 \%$.

\begin{tabular}{|c|c|c|c|}
\hline & \multicolumn{3}{|c|}{ Dependent variable: } \\
\hline & Abn AMF EA Volume & Abn EA Tot Volume & $\begin{array}{c}\text { AMF Vol as a Frac of } \\
\text { Tot Volume }\end{array}$ \\
\hline & (i) & (ii) & (iii) \\
\hline Abs_UG & $\begin{array}{c}0.653^{* * *} \\
(4.04)\end{array}$ & $\begin{array}{l}13.062^{* * *} \\
(8.45)\end{array}$ & $\begin{array}{l}0.050 \\
(0.84)\end{array}$ \\
\hline Abs_UE & $\begin{array}{l}0.182 \\
(0.71)\end{array}$ & $\begin{array}{c}14.193^{* * *} \\
(4.12)\end{array}$ & $\begin{array}{c}-0.229 * * * \\
(-2.79)\end{array}$ \\
\hline EarnLoss & $\begin{array}{c}-0.008 * * * \\
(-2.76)\end{array}$ & $\begin{array}{c}-0.131 * * * \\
(-5.05)\end{array}$ & $\begin{array}{l}-0.001 \\
(-1.02)\end{array}$ \\
\hline GuidanceLoss & $\begin{array}{c}-0.015^{* * *} \\
(-3.23)\end{array}$ & $\begin{array}{c}-0.081^{*} \\
(-1.72)\end{array}$ & $\begin{array}{c}-0.006 * * * \\
(-3.13)\end{array}$ \\
\hline MktCap & $\begin{array}{c}-0.011 * * * \\
(-14.41)\end{array}$ & $\begin{array}{c}-0.126 * * * \\
(-15.79)\end{array}$ & $\begin{array}{c}-0.003^{* * *} \\
(-8.43)\end{array}$ \\
\hline BTM & $\begin{array}{c}-0.005^{* * *} \\
(-4.30)\end{array}$ & $\begin{array}{c}-0.141 * * * \\
(-13.32)\end{array}$ & $\begin{array}{c}0.001^{* *} \\
(2.07)\end{array}$ \\
\hline Volatility & $\begin{array}{c}-0.009 * * * \\
(-5.97)\end{array}$ & $\begin{array}{l}-0.024 * \\
(-1.81)\end{array}$ & $\begin{array}{c}-0.004 * * * \\
(-5.92)\end{array}$ \\
\hline Firm and Date $\mathrm{Cl}$ & & & \\
\hline SEs & Yes & Yes & Yes \\
\hline Qtr Fixed Effects & Yes & Yes & Yes \\
\hline Observations & 28,731 & 28,731 & 28,731 \\
\hline R2 & 0.042 & 0.064 & 0.041 \\
\hline
\end{tabular}




\section{Table 4: Analysis of Bundled Announcements in which UG and UE are Inconsistent}

This table reports abnormal volume when unexpected earnings (UE) and unexpected guidance news (UG) are directionally inconsistent. $U E$ is calculated relative to the IBES consensus forecast. $U G$ is calculated using the conditional expectations model in Rogers and Van Buskirk (2013). We begin with all firm-quarters with bundled guidance $(\mathrm{N}=28,731)$. We further divide this sample into positive $U E(\mathrm{~N}=23,180)$ and negative $U E$ ( $\mathrm{N}=5,551)$ observations. Panel A reports the fraction of each group where $U G$ and $U E$ are directionally inconsistent. We then use the indicator variable Inconsistent to denote observations where $U G$ and $U E$ are inconsistent. Panel B reports results when we regress Abn AMF EA Volume, Abn EA Tot Volume, and AMF Vol as a Frac of Tot Volume on the absolute value of unexpected earnings (Abs_UE), Inconsistent, Abs_UE x Inconsistent, and a set of control variables. Controls include: MktCap, BTM, and Volatility and are standardized to have a mean (standard deviation) of 0 (1). Fiscal year-quarter fixed effects are included in all models. Standard errors are clustered by firm and EA date. All variables are defined in Appendix A. T-statistics are in parentheses. *** indicates significance at 1\%; ** at 5\%; and $*$ at $10 \%$.

Panel A: Descriptive Statistics, Inconsistent UG and UE

\begin{tabular}{lrr}
\hline & $\mathrm{N}$ & Mean \\
\cline { 2 - 3 } \% Inconsistent UG and UE & 28,731 & 0.56 \\
\% Inconsistent, for Positive UE & 23,180 & 0.55 \\
\% Inconsistent, for Negative UE & 5,551 & 0.59 \\
\hline
\end{tabular}

Panel B: Effect of Inconsistent UG and UE on the Relation between Volume and Abs_UE

\begin{tabular}{|c|c|c|c|}
\hline & \multicolumn{3}{|c|}{ Dependent variable: } \\
\hline & Abn AMF EA Volume & Abn EA Tot Volume & $\begin{array}{c}\text { AMF Vol as a Frac of } \\
\text { Tot Volume }\end{array}$ \\
\hline & (i) & (ii) & (iii) \\
\hline Abs_UE & $\begin{array}{c}1.522 * * * \\
(3.93)\end{array}$ & $\begin{array}{l}32.480 * * * \\
(7.16)\end{array}$ & $\begin{array}{l}-0.048 \\
(-0.39)\end{array}$ \\
\hline Inconsistent & $\begin{array}{l}0.004^{*} \\
(1.93)\end{array}$ & $\begin{array}{l}-0.012 \\
(-0.72)\end{array}$ & $\begin{array}{l}0.001 \\
(1.42)\end{array}$ \\
\hline Abs_UE $x$ Inconsistent & $\begin{array}{c}-1.586^{* * *} \\
(-3.58)\end{array}$ & $\begin{array}{c}-19.044^{* * *} \\
(-3.45)\end{array}$ & $\begin{array}{l}-0.238 \\
(-1.63)\end{array}$ \\
\hline EarnLoss & $\begin{array}{c}-0.007 * * \\
(-2.39)\end{array}$ & $\begin{array}{c}-0.111^{* * *} \\
(-4.32)\end{array}$ & $\begin{array}{l}-0.001 \\
(-0.94)\end{array}$ \\
\hline GuidanceLoss & $\begin{array}{c}-0.013^{* * *} \\
(-2.69)\end{array}$ & $\begin{array}{l}-0.023 \\
(-0.48)\end{array}$ & $\begin{array}{c}-0.006 * * * \\
(-3.03)\end{array}$ \\
\hline MktCap & $\begin{array}{c}-0.011^{* * *} \\
(-14.37)\end{array}$ & $\begin{array}{c}-0.126 * * * \\
(-15.56)\end{array}$ & $\begin{array}{c}-0.003^{* * *} \\
(-8.42)\end{array}$ \\
\hline BTM & $\begin{array}{c}-0.005^{* * *} \\
(-4.01)\end{array}$ & $\begin{array}{c}-0.132 * * * \\
(-12.53)\end{array}$ & $\begin{array}{c}0.001^{* *} \\
(2.09)\end{array}$ \\
\hline Volatility & $\begin{array}{c}-0.008^{* * *} \\
(-5.47)\end{array}$ & $\begin{array}{l}-0.004 \\
(-0.32)\end{array}$ & $\begin{array}{c}-0.004 * * * \\
(-5.99)\end{array}$ \\
\hline $\begin{array}{l}\text { P-value that Sum }\left\{A b s \_U E+A b s \_U E x\right. \\
\text { Inconsistent }\} \text { is different from zero }\end{array}$ & 0.767 & $2 \mathrm{e}-04 * * *$ & $2 \mathrm{e}-04 * * *$ \\
\hline Firm and Date Clustered SEs & Yes & Yes & Yes \\
\hline Qtr Fixed Effects & Yes & Yes & Yes \\
\hline Observations & 28,731 & 28,731 & 28,731 \\
\hline
\end{tabular}




\section{Table 5: Analysis of Bundled Guidance Earnings Announcements and Directional Trading}

This table presents results of regressing AMF EA BSI and Total EA BSI on unexpected guidance and unexpected earnings. The sample includes only firm-quarters with bundled guidance. Controls include: MktCap, BTM, and Volatility and are standardized to have a mean (standard deviation) of 0 (1). Fiscal year-quarter fixed effects are included in all models. Standard errors are clustered by firm and EA date. All variables are defined in Appendix A. T-statistics are in parentheses. ${ }^{* * *}$ indicates significance at $1 \%$; $* *$ at $5 \%$; and $*$ at $10 \%$.

\begin{tabular}{lcc}
\hline & \multicolumn{2}{c}{ Dependent variable: } \\
\cline { 2 - 3 } & AMF EA BSI & Total EA BSI \\
\cline { 2 - 3 }$U$ UE & $(\mathrm{i})$ & (ii) \\
& $2.665^{* * *}$ & 0.017 \\
EarnLoss & $(3.24)$ & $(0.29)$ \\
& 0.838 & -0.044 \\
GuidanceLoss & $(0.45)$ & $(-0.36)$ \\
& -0.036 & -0.003 \\
MktCap & $(-1.63)$ & $(-1.37)$ \\
& -0.028 & -0.002 \\
BTM & $(-1.07)$ & $(-0.63)$ \\
& 0.001 & 0.001 \\
Volatility & $(0.18)$ & $(1.18)$ \\
& -0.002 & $0.003^{* * *}$ \\
Firm and Date & $(-0.34)$ & $(3.32)$ \\
Clustered SEs & $0.027^{* * *}$ & $-0.011^{* * *}$ \\
Qtr Fixed Effects & $(2.98)$ & $(-10.59)$ \\
Observations & & \\
R2 & Yes & Yes \\
\hline
\end{tabular}


Table 6: Analysis of Bundled Guidance Earnings Announcements and Directional Trading, Inconsistent UG and UE

This table presents results of regressing AMF EA BSI and Total EA BSI on unexpected earnings and unexpected guidance, and tests whether the coefficient differs for firm-quarters with inconsistent unexpected guidance and unexpected earnings. The sample includes only firmquarters with bundled guidance. Controls include: MktCap, BTM, and Volatility and are standardized to have a mean (standard deviation) of 0 (1). Fiscal year-quarter fixed effects are included in all models. Standard errors are clustered by firm and EA date. All variables are defined in Appendix A. T-statistics are in parentheses. ${ }^{* *}$ indicates significance at $1 \%$; ${ }^{* *}$ at $5 \%$; and ${ }^{*}$ at $10 \%$.

\begin{tabular}{|c|c|c|c|c|}
\hline & \multicolumn{4}{|c|}{ Dependent variable: } \\
\hline & \multicolumn{2}{|c|}{ AMF EA BSI } & \multicolumn{2}{|c|}{ Total EA BSI } \\
\hline & (i) & (ii) & (iii) & (iv) \\
\hline Inconsistent & $\begin{array}{l}0.002 \\
(0.21)\end{array}$ & $\begin{array}{l}0.005 \\
(0.46)\end{array}$ & $\begin{array}{c}0.000 \\
(-0.32)\end{array}$ & $\begin{array}{l}-0.001 \\
(-0.50)\end{array}$ \\
\hline$U E$ & $\begin{array}{c}3.579 * * \\
(1.97)\end{array}$ & & $\begin{array}{l}0.077 \\
(0.41)\end{array}$ & \\
\hline UE $\times$ Inconsistent & $\begin{array}{l}-4.320 \\
(-1.35)\end{array}$ & & $\begin{array}{l}-0.188 \\
(-0.87)\end{array}$ & \\
\hline$U G$ & & $\begin{array}{c}2.683 * * * \\
(3.15)\end{array}$ & & $\begin{array}{l}0.098 \\
(1.21)\end{array}$ \\
\hline UG $\times$ Inconsistent & & $\begin{array}{l}0.064 \\
(0.04)\end{array}$ & & $\begin{array}{l}-0.180 \\
(-1.42)\end{array}$ \\
\hline EarnLoss & $\begin{array}{l}-0.036^{*} \\
(-1.67)\end{array}$ & $\begin{array}{l}-0.038^{*} \\
(-1.72)\end{array}$ & $\begin{array}{l}-0.003 \\
(-1.39)\end{array}$ & $\begin{array}{l}-0.002 \\
(-1.25)\end{array}$ \\
\hline GuidanceLoss & $\begin{array}{l}-0.041 \\
(-1.56)\end{array}$ & $\begin{array}{l}-0.027 \\
(-1.02)\end{array}$ & $\begin{array}{l}-0.002 \\
(-0.58)\end{array}$ & $\begin{array}{l}-0.002 \\
(-0.69)\end{array}$ \\
\hline MktCap & $\begin{array}{l}0.001 \\
(0.19)\end{array}$ & $\begin{array}{l}0.001 \\
(0.18)\end{array}$ & $\begin{array}{l}0.001 \\
(1.18)\end{array}$ & $\begin{array}{l}0.001 \\
(1.17)\end{array}$ \\
\hline BTM & $\begin{array}{l}-0.004 \\
(-0.52)\end{array}$ & $\begin{array}{l}-0.002 \\
(-0.34)\end{array}$ & $\begin{array}{l}0.003 * * * \\
(3.33)\end{array}$ & $\begin{array}{c}0.003^{* * *} \\
(3.32)\end{array}$ \\
\hline Volatility & $\begin{array}{l}0.025^{* * *} \\
(2.84)\end{array}$ & $\begin{array}{l}0.027^{* * *} \\
(3.06)\end{array}$ & $\begin{array}{c}-0.011^{* * *} \\
(-10.67)\end{array}$ & $\begin{array}{c}-0.011^{* * *} \\
(-10.67)\end{array}$ \\
\hline $\begin{array}{l}\mathrm{P} \text {-value that } \operatorname{Sum}\{U E+U E x \\
\text { Inconsistent }\} \text { is different from zero }\end{array}$ & 0.777 & & 0.430 & \\
\hline $\begin{array}{l}\text { P-value that } \operatorname{Sum}\{U G+U G x \\
\text { Inconsistent }\} \text { is different from zero }\end{array}$ & & $0.0666^{*}$ & & 0.368 \\
\hline Observations & 28,731 & 28,731 & 28,731 & 28,731 \\
\hline R2 & 0.006 & 0.007 & 0.083 & 0.083 \\
\hline
\end{tabular}


This table presents results of regressing Abn AMF EA Volume, Abn EA Tot Volume, and AMF Vol as a Frac of Tot Volume on the absolute value of unexpected guidance, the absolute value of unexpected earnings, and the absolute value of the guidance bias. The sample includes only firm-quarters with bundled guidance. Controls include: MktCap, BTM, and Volatility and are standardized to have a mean (standard deviation) of 0 (1). Fiscal year-quarter fixed effects are included in all models. Standard errors are clustered by firm and EA date. All variables are defined in Appendix A. T-statistics are in parentheses. *** indicates significance at $1 \%$;* at $5 \%$; and $*$ at $10 \%$.

\begin{tabular}{lccc}
\hline & \multicolumn{3}{c}{ Dependent variable: } \\
\cline { 2 - 4 } & Abn AMF EA Volume & Abn EA Tot Volume & AMF Vol as a Frac of \\
\cline { 2 - 4 } Abs_UG & $(\mathrm{i})$ & $(\mathrm{ii})$ & $(\mathrm{iii})$ \\
& $0.781^{* * *}$ & $14.093^{* * *}$ & 0.098 \\
Abs_UE & $(4.49)$ & $(7.34)$ & $(1.56)$ \\
& 0.209 & $14.412^{* * *}$ & $-0.219^{* *}$ \\
Abs_Guide_Bias & $(0.78)$ & $(4.14)$ & $(-2.56)$ \\
& $-0.126^{* * *}$ & $-1.012^{*}$ & $-0.046^{* * *}$ \\
EarnLoss & $(-3.97)$ & $(-1.87)$ & $(-3.68)$ \\
& $-0.008^{* * *}$ & $-0.129^{* * *}$ & -0.001 \\
GuidanceLoss & $(-2.67)$ & $(-4.99)$ & $(-0.94)$ \\
MktCap & $-0.016^{* * *}$ & $-0.082^{*}$ & $-0.006^{* * *}$ \\
& $(-3.30)$ & $(-1.77)$ & $(-3.19)$ \\
BTM & $-0.011^{* * *}$ & $-0.126^{* * *}$ & $-0.003^{* * *}$ \\
& $(-14.31)$ & $(-15.79)$ & $(-8.33)$ \\
Volatility & $-0.005^{* * *}$ & $-0.138^{* * *}$ & $0.001^{* *}$ \\
Firm and Date & $(-3.93)$ & $(-12.62)$ & $(2.33)$ \\
Clustered SEs & $-0.008^{* * *}$ & $-0.020^{*}$ & $-0.004^{* * *}$ \\
Qtr Fixed Effects & $(-5.89)$ & $(-1.67)$ & $(-5.87)$ \\
Observations & & & \\
R2 & Yes & Yes & Yes \\
\hline
\end{tabular}




\section{Table 8: Analysis of Bundled Guidance Earnings Announcements and Directional Trading, Guidance Bias}

This table presents results of regressing AMF EA BSI and Total EA BSI on unexpected earnings (UE), unexpected guidance ( $U G$ ), and guidance bias. The Guide_Bias variable (used in columns (i) and (vii)) is the difference between the guidance and the actual subsequently reported earnings. The Bias_ExtremeY variable is an indicator variable that is set to 1 when guidance bias is in the most extreme (i.e., the most excessively positive) $Y$ decile(s). For example, in column (ii), the indicator variable is set to 1 when the guidance bias is in the top decile. In column (iii), it is set to 1 when guidance bias is in the top two deciles. The sample includes only firm-quarters with bundled guidance. Controls include: MktCap, BTM, and Volatility and are standardized to have a mean (standard deviation) of 0 (1). Fiscal year-quarter fixed effects are included in all models. Standard errors are clustered by firm and EA date. All variables are defined in Appendix A. T-statistics are in parentheses. *** indicates significance at $1 \%$; ** at $5 \%$; and * at $10 \%$.

\begin{tabular}{|c|c|c|c|c|c|c|c|c|}
\hline & \multicolumn{8}{|c|}{ Dependent variable: } \\
\hline & \multicolumn{6}{|c|}{ AMF EA BSI } & \multicolumn{2}{|c|}{ Total EA BSI } \\
\hline & (i) & (ii) & (iii) & (iv) & (v) & (vi) & (vii) & (viii) \\
\hline$U G$ & $\begin{array}{c}2.645^{* * *} \\
(3.23)\end{array}$ & $\begin{array}{c}2.596 * * * \\
(3.19)\end{array}$ & $\begin{array}{c}2.628^{* * * *} \\
(3.22)\end{array}$ & $\begin{array}{c}2.661^{* * *} \\
(3.25)\end{array}$ & $\begin{array}{c}2.670 * * * \\
(3.25)\end{array}$ & $\begin{array}{c}2.663 * * * \\
(3.24)\end{array}$ & $\begin{array}{l}0.019 \\
(0.33)\end{array}$ & $\begin{array}{l}0.016 \\
(0.28)\end{array}$ \\
\hline$U E$ & $\begin{array}{l}0.588 \\
(0.35)\end{array}$ & $\begin{array}{l}0.505 \\
(0.29)\end{array}$ & $\begin{array}{l}0.472 \\
(0.26)\end{array}$ & $\begin{array}{l}0.645 \\
(0.36)\end{array}$ & $\begin{array}{l}0.708 \\
(0.39)\end{array}$ & $\begin{array}{l}0.887 \\
(0.48)\end{array}$ & $\begin{array}{l}-0.021 \\
(-0.17)\end{array}$ & $\begin{array}{l}-0.048 \\
(-0.40)\end{array}$ \\
\hline Guide_Bias & $\begin{array}{l}-0.272 \\
(-0.97)\end{array}$ & & & & & & $\begin{array}{l}0.025 \\
(0.56)\end{array}$ & \\
\hline Bias_Extreme1 & & $\begin{array}{c}-0.046^{* * *} \\
(-2.85)\end{array}$ & & & & & & $\begin{array}{l}-0.001 \\
(-0.18)\end{array}$ \\
\hline Bias_Extreme2 & & & $\begin{array}{c}-0.034^{* *} \\
(-2.57)\end{array}$ & & & & & \\
\hline Bias_Extreme3 & & & & $\begin{array}{l}-0.016 \\
(-1.45)\end{array}$ & & & & \\
\hline Bias_Extreme4 & & & & & $\begin{array}{l}-0.009 \\
(-0.93)\end{array}$ & & & \\
\hline Bias_Extreme5 & & & & & & $\begin{array}{l}0.003 \\
(0.25)\end{array}$ & & \\
\hline EarnLoss & $\begin{array}{l}-0.035 \\
(-1.61)\end{array}$ & $\begin{array}{l}-0.034 \\
(-1.56)\end{array}$ & $\begin{array}{l}-0.035 \\
(-1.60)\end{array}$ & $\begin{array}{l}-0.035 \\
(-1.63)\end{array}$ & $\begin{array}{l}-0.036 \\
(-1.64)\end{array}$ & $\begin{array}{l}-0.035 \\
(-1.61)\end{array}$ & $\begin{array}{l}-0.003 \\
(-1.40)\end{array}$ & $\begin{array}{l}-0.003 \\
(-1.36)\end{array}$ \\
\hline GuidanceLoss & $\begin{array}{l}-0.028 \\
(-1.09)\end{array}$ & $\begin{array}{l}-0.027 \\
(-1.04)\end{array}$ & $\begin{array}{l}-0.027 \\
(-1.04)\end{array}$ & $\begin{array}{l}-0.028 \\
(-1.06)\end{array}$ & $\begin{array}{l}-0.028 \\
(-1.07)\end{array}$ & $\begin{array}{l}-0.028 \\
(-1.07)\end{array}$ & $\begin{array}{l}-0.002 \\
(-0.61)\end{array}$ & $\begin{array}{l}-0.002 \\
(-0.62)\end{array}$ \\
\hline MktCap & $\begin{array}{l}0.001 \\
(0.13)\end{array}$ & $\begin{array}{l}0.000 \\
(0.08)\end{array}$ & $\begin{array}{l}0.000 \\
(0.01)\end{array}$ & $\begin{array}{l}0.000 \\
(0.07)\end{array}$ & $\begin{array}{l}0.001 \\
(0.12)\end{array}$ & $\begin{array}{l}0.001 \\
(0.19)\end{array}$ & $\begin{array}{l}0.001 \\
(1.20)\end{array}$ & $\begin{array}{l}0.001 \\
(1.17)\end{array}$ \\
\hline$B T M$ & $\begin{array}{l}-0.002 \\
(-0.24)\end{array}$ & $\begin{array}{c}0.000 \\
(-0.06)\end{array}$ & $\begin{array}{l}-0.001 \\
(-0.09)\end{array}$ & $\begin{array}{l}-0.002 \\
(-0.25)\end{array}$ & $\begin{array}{l}-0.002 \\
(-0.31)\end{array}$ & $\begin{array}{l}-0.002 \\
(-0.33)\end{array}$ & $\begin{array}{c}0.003 * * * \\
(3.29)\end{array}$ & $\begin{array}{c}0.003^{* * *} \\
(3.38)\end{array}$ \\
\hline Volatility & $\begin{array}{c}0.028 * * * \\
(3.19)\end{array}$ & $\begin{array}{c}0.029 * * * \\
(3.27)\end{array}$ & $\begin{array}{c}0.028^{* * *} \\
(3.11)\end{array}$ & $\begin{array}{c}0.027 * * * \\
(3.08)\end{array}$ & $\begin{array}{c}0.027^{* * *} \\
(3.01)\end{array}$ & $\begin{array}{c}0.027 * * * \\
(2.96)\end{array}$ & $\begin{array}{c}-0.011 * * * \\
(-10.50)\end{array}$ & $\begin{array}{c}-0.011 * * * \\
(-10.56)\end{array}$ \\
\hline
\end{tabular}


Firm and Date

Clustered SEs

Qtr Fixed Effects

Observations

\begin{tabular}{cccccc|cc} 
& & & & & & \\
Yes & Yes & Yes & Yes & Yes & Yes & Yes & Yes \\
Yes & Yes & Yes & Yes & Yes & Yes & Yes & Yes \\
28,731 & 28,731 & 28,731 & 28,731 & 28,731 & 28,731 & 28,731 & 28,731 \\
0.007 & 0.007 & 0.007 & 0.007 & 0.007 & 0.007 & 0.083 & 0.083 \\
\hline
\end{tabular}




\section{Table 9: Analysis of Speed of Price Adjustment}

Panel A presents descriptive statistics of firm-quarters with bundled guidance where the $[0,+63]$ returns are also in the top or bottom quintile. Panel B presents results of regressing the fraction of $[0,+63]$ returns that occurs in days $[0,+4]$ on abnormal volume variables. Controls include: MktCap, BTM, and Volatility and are standardized to have a mean (standard deviation) of 0 (1). Fiscal year-quarter fixed effects are included in all models. Standard errors are clustered by firm and EA date. All variables are defined in Appendix A. T-statistics are in parentheses. $* * *$ indicates significance at $1 \%$; ** at $5 \%$; and * at $10 \%$.

Panel A: Descriptive Statistics, Extreme Returns Sample

\begin{tabular}{|c|c|c|c|c|c|c|c|c|}
\hline & $\mathrm{N}$ & Mean & $\begin{array}{c}\text { Std } \\
\text { Dev }\end{array}$ & P1 & P25 & Median & P75 & P99 \\
\hline$[0,+4]$ Ret as a Fraction of $[0,+63]$ Ret & 10,904 & 0.26 & 0.64 & -0.97 & 0.01 & 0.23 & 0.46 & 1.79 \\
\hline Abn AMF EA Volume & 10,904 & 0.08 & 0.12 & 0.00 & 0.01 & 0.04 & 0.10 & 0.69 \\
\hline AMF EA Vol as a Frac of Tot Volume & 10,904 & 0.04 & 0.05 & 0.00 & 0.01 & 0.02 & 0.05 & 0.24 \\
\hline Concordant AMF EA Trading & 10,904 & 0.21 & 0.40 & 0.00 & 0.00 & 0.00 & 0.00 & 1.00 \\
\hline Abs_UE & 10,904 & 0.00 & 0.01 & 0.00 & 0.00 & 0.00 & 0.00 & 0.03 \\
\hline EarnLoss & 10,904 & 0.14 & 0.34 & 0.00 & 0.00 & 0.00 & 0.00 & 1.00 \\
\hline GuidanceLoss & 10,904 & 0.05 & 0.22 & 0.00 & 0.00 & 0.00 & 0.00 & 1.00 \\
\hline
\end{tabular}

Panel B: Effect of AMF EA Participation on the Speed of Price Adjustment

\begin{tabular}{lccc}
\hline & \multicolumn{3}{c}{ Dependent variable: } \\
\cline { 2 - 4 } & \multicolumn{3}{c}{$[0,+4]$ Ret as a Fraction of [0,+63] Ret } \\
\cline { 2 - 4 } Abn AMF EA Volume & (i) & $(\mathrm{ii})$ & \\
AMF Vol as a Frac of Tot Volume & $\left(8.943^{* * *}\right.$ & & \\
& & $0.237^{* *}$ & \\
Concordant AMF EA Trading & & $(2.01)$ & 0.016 \\
& & & $(1.00)$ \\
Abs_UE & & & -0.030 \\
& -0.188 & 0.045 & $(-0.03)$ \\
EarnLoss & $(-0.18)$ & $(0.04)$ & $-0.045^{* *}$ \\
GuidanceLoss & $-0.042^{* *}$ & $-0.044^{* *}$ & $(-2.15)$ \\
MktCap & $(-2.03)$ & $(-2.14)$ & 0.022 \\
& 0.027 & 0.023 & $(0.95)$ \\
BTM & $(1.17)$ & $(1.01)$ & -0.004 \\
Volatility & 0.002 & -0.004 & $(-0.44)$ \\
Firm and Date Clustered SEs & $(0.15)$ & $(-0.40)$ & -0.010 \\
Extreme [0,+63] Returns Only & -0.008 & -0.010 & $(-1.34)$ \\
Observations & $(-1.03)$ & $(-1.30)$ & $-0.038^{* * *}$ \\
R2 & $-0.031^{* * *}$ & $-0.037^{* * *}$ & $(-3.38)$ \\
& $(-2.69)$ & $(-3.22)$ & Yes \\
& Yes & Yes & Yes \\
\end{tabular}




\section{Table 10: Analysis of Guidance News Drift}

Panel A presents descriptive statistics of firm-quarters with bundled guidance and market cap in the first and second tercile. Panel B presents results of regressing abnormal $[+4,+63]$ returns on unexpected guidance $(U G)$, and tests whether the post- $U G$ price drift effect is a function of the magnitude and/or the direction of AMF trading during the earnings announcement. We use three different empirical proxies to capture a high level of AMF participation during the EA. The first proxy, High Abn AMF EA Volume, is an indicator variable set to 1 when Abn AMF EA Volume is above the median (see column (ii)). ${ }^{28}$ The second proxy, High AMF Vol as a Frac of Tot Volume, is an indicator variable set to 1 when $A M F$ Vol as a Frac of Tot Volume is above the median (see column (iii)). The third proxy, Concordant AMF EA Trading, is an indicator variable set to 1 for firm-quarters with both AMF EA BSI and $U G$ in the top quintile, or both AMF EA BSI and UG in the bottom quintile (see column (iv)). In each of the three instances, we include a LowAMFVariable, which is defined as the ones' complement of each of the HighAMFVariable variables in their respective columns (e.g., in column ii, the HighAMFVariable is High Abn AMF EA Volume and the LowAMFVariable is Low Abn AMF EA Volume) ${ }^{29}$ Controls include: MktCap, $B T M$, and Volatility and are standardized to have a mean (standard deviation) of 0 (1). Standard errors are clustered by firm and EA date. All variables are defined in Appendix A. T-statistics are in parentheses. *** indicates significance at $1 \%$; ** at $5 \%$; and * at $10 \%$.

\section{Panel A: Descriptive Statistics, Small Firm Sample}

\begin{tabular}{|c|c|c|c|c|c|c|c|c|}
\hline & $\mathrm{N}$ & Mean & $\begin{array}{c}\text { Std } \\
\text { Dev }\end{array}$ & P1 & P25 & Median & P75 & P99 \\
\hline AbnRet $[+4,+63]$ & 17,049 & 0.00 & 0.16 & -0.38 & -0.10 & -0.01 & 0.09 & 0.45 \\
\hline$U G$ & 17,049 & 0.00 & 0.01 & -0.04 & 0.00 & 0.00 & 0.00 & 0.02 \\
\hline$U E$ & 17,049 & 0.00 & 0.01 & -0.02 & 0.00 & 0.00 & 0.00 & 0.01 \\
\hline Abn AMF EA Volume & 17,049 & 0.09 & 0.13 & 0.00 & 0.01 & 0.04 & 0.11 & 0.69 \\
\hline AMF EA Vol as a Frac of Tot Volume & 17,049 & 0.04 & 0.05 & 0.00 & 0.00 & 0.02 & 0.05 & 0.25 \\
\hline Concordant AMF EA Trading & 17,049 & 0.21 & 0.41 & 0.00 & 0.00 & 0.00 & 0.00 & 1.00 \\
\hline Abn EA Tot Volume & 17,049 & 1.96 & 1.10 & 0.56 & 1.24 & 1.67 & 2.33 & 6.54 \\
\hline
\end{tabular}

\footnotetext{
${ }^{28}$ To control for firm size and unexpected earnings, we first sort each observation into three $U E$ terciles. Within each of the three $U E$ terciles, we sort each observation into three market cap terciles, forming nine subgroups. We then classify each firm-quarter observation based on its AMF participation variable into above-median and belowmedian categories, within each of the nine subgroups. We do this ranking within subgroups and within year, to mitigate the effect that the magnitude of earnings news and firm liquidity may have on the magnitude of the $U G$ drift.

${ }^{29}$ Specifically, the coefficient on $U G \times H i g h A M F$ Variable is equivalent to the coefficient on UG when HighAMFVariable $=1$. The coefficient on $U G \times$ LowAMFVariable is equivalent to the coefficient on UG when LowAMFVariable $=1$. We omit the main effect $U G$ from the regression, because it is a linear combination of $U G \times$ HighAMFVariable and $U G \times$ LowAMFVariable. We omit the main effect LowAMFVariable from the regression, because it is a linear combination of 1 and HighAMFVariable (and the regression estimates an intercept $\alpha)$.
} 
Panel B: Effect of AMF EA Participation on Guidance News Drift

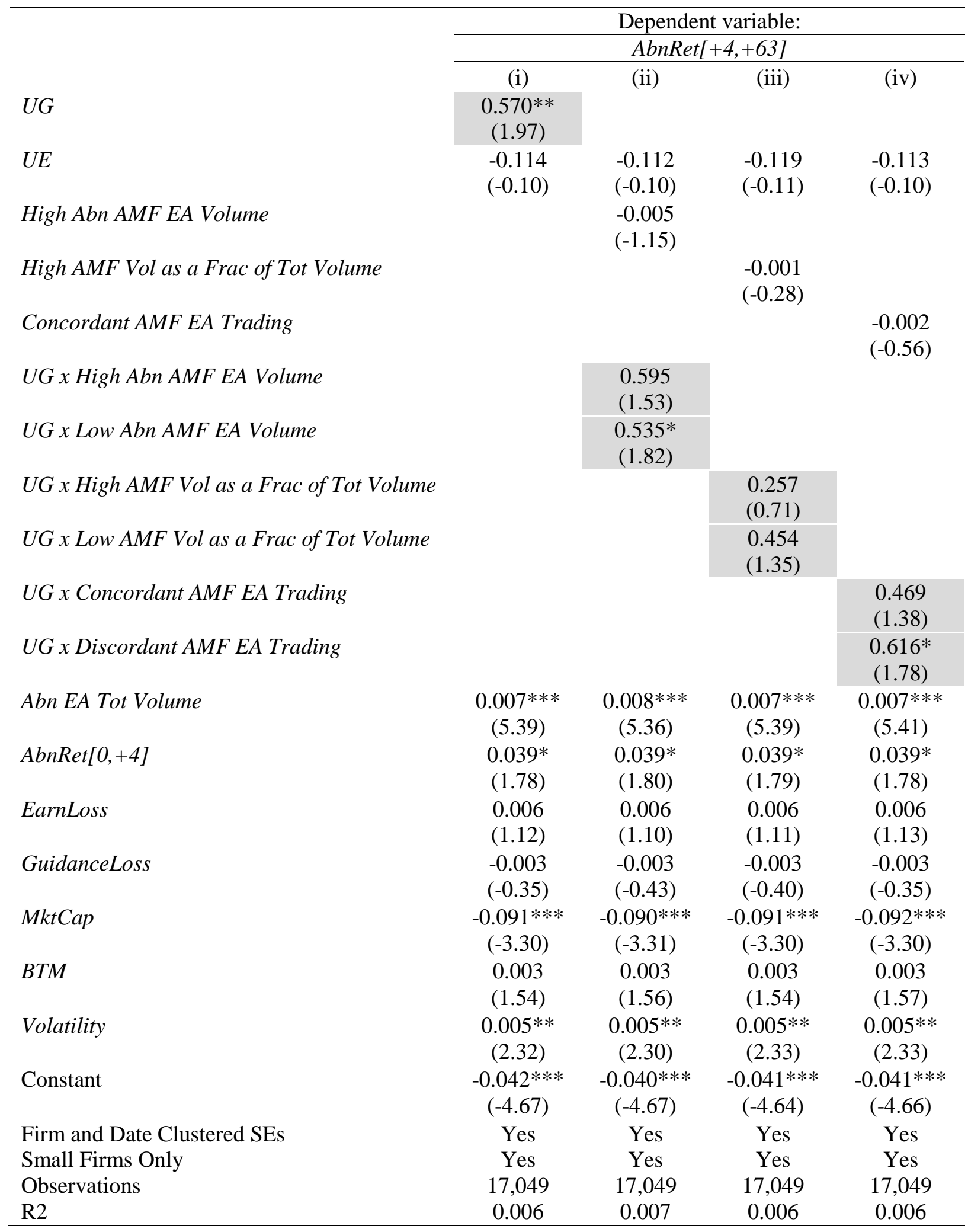


